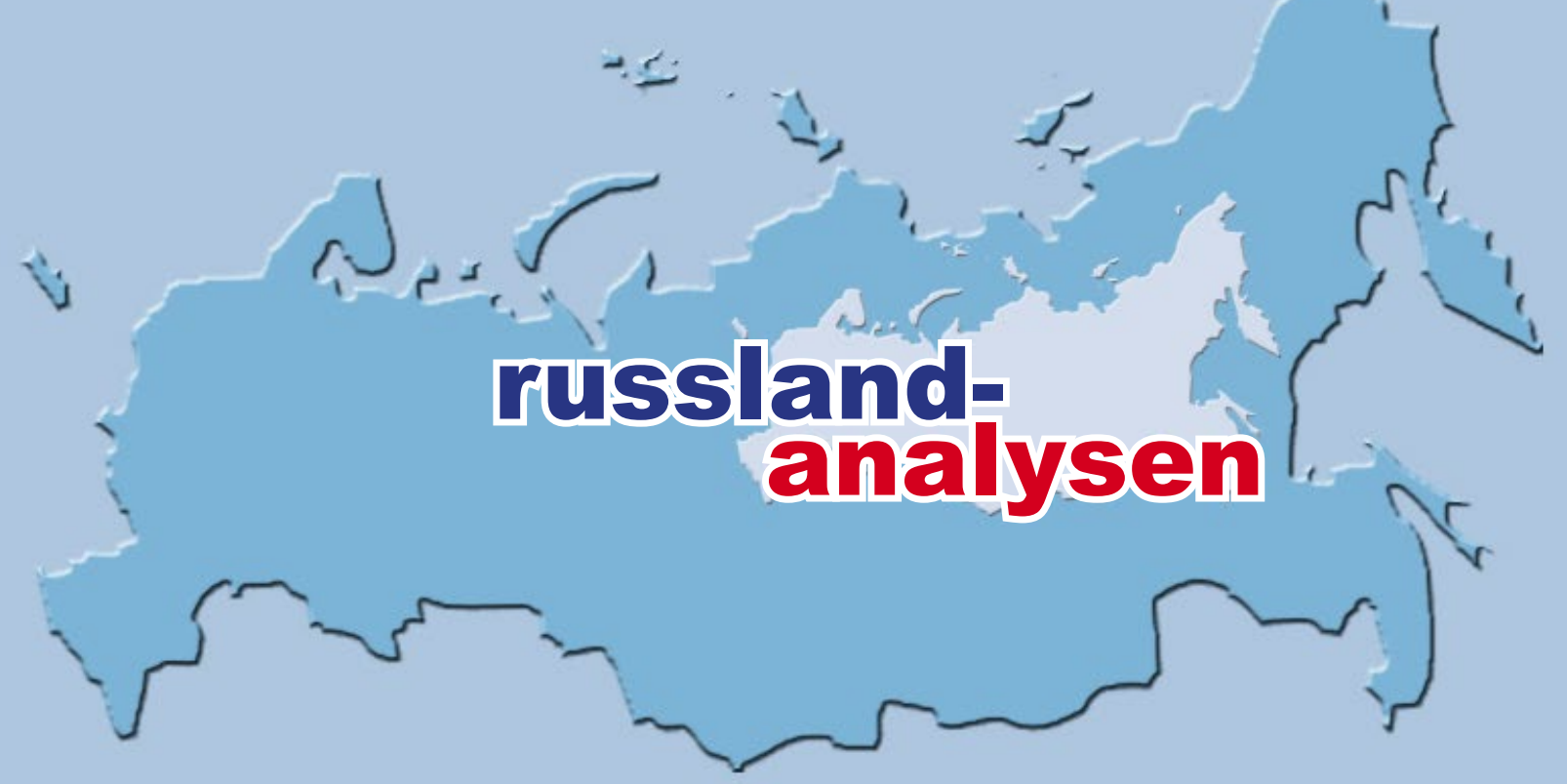

http://www.laender-analysen.de/russland/

\title{
ENERGIEPOLITIK IN RUSSLAND
}

ANALYSE

Exportoptionen für russisches Erdgas nach dem Scheitern von South Stream

Andreas Heinrich, Bremen

ANALYSE

Gazproms neue Strategie für Europa

Julia Kusznir, Bremen

TABELLEN UND GRAFIKEN ZUM TEXT

Russische Erdgasexporte: Umfang, Pipelines, Abnehmerländer

NOTIZEN AUS MOSKAU

Wirtschaftskrise in Russland - und keiner protestiert. Warum?

Jens Siegert, Moskau

UMFRAGE

Wirtschaftskrise und soziale Lage in Umfragen

Russen zum Einsatz von Streitkräften in Syrien

AUS RUSSISCHEN BLOGS

Swetlana Alexijewitsch - eine russische Schriftstellerin?

CHRONIK

8. - 22. Oktober 2015

D) - Deutsche Gesellschaft für Osteuropakunde e.V.
Forschungsstelle Osteuropa an der Universität Bremen 


\section{Exportoptionen für russisches Erdgas nach dem Scheitern von South Stream}

Andreas Heinrich, Bremen

\section{Zusammenfassung}

Nach den wiederholten Gaskonflikten mit der Ukraine setzt Gazprom auch weiterhin auf Pipelineprojekte, die derzeitige Transitländer möglichst umgehen. Diese strategischen Überlegungen lassen aber wirtschaftliche, technische und rechtliche Aspekte solcher Projekte oft in den Hintergrund treten. Dies reduziert die Wahrscheinlichkeit, dass die Projekte je realisiert werden.

\section{Einleitung}

Während Gazproms Exporte seit 2007 in der Tendenz rückläufig sind (siehe Grafik 1 auf S. 8), sind nur $4 \%$ der heimischen Gaslieferungen für Gazprom wirklich profitabel. Daher muss Gazprom weiter sein Augenmerk auf Exporte richten, um Gewinne zu erzielen.

Im Folgenden sollen Gazproms Exportoptionen zur Belieferung des EU-Marktes, die Bedeutung russischer Exporte nach Asien für die europäische Erdgasversorgung und die Auswirkungen von Gazproms Pipelineplänen für die Ukraine als Transitland untersucht werden.

\section{Exportpläne}

Außerhalb des Gebietes der ehemaligen Sowjetunion sind nach wie vor Europa und die Türkei die Hauptabsatzmärkte für russisches Erdgas. Die Belieferung dieser Märkte erfolgt derzeit über sieben zentrale Exportpipelines, die in Tabelle 1 auf S. 9 aufgeführt werden. Zusätzlich hat Gazprom in den letzten Jahren drei große Projekte zur Ausweitung der Exportkapazitäten nach Europa sowie zwei weitere in Richtung Asien diskutiert.

Die von Gazprom in den letzten Jahren angestoßenen europäischen Pipelineprojekte hatten und haben in erster Linie das Ziel, die Bedeutung der Ukraine als Transitland für russisches Erdgas zu verringern. Während zurzeit die Pipelines durch die Ukraine eine nominelle Kapazität von $183 \mathrm{Mrd}$. Kubikmetern pro Jahr haben, plant Gazprom die Kapazitäten der Pipelines, die die Ukraine umgehen, von derzeit $125 \mathrm{Mrd}$. Kubikmetern bis 2020 auf insgesamt $215 \mathrm{Mrd}$. Kubikmeter auszubauen. Damit würde Gazprom seine Exportkapazitäten nicht nur insgesamt deutlich ausweiten, sondern auch die Bedeutung der Ukraine als Transitland verringern. Gazprom selbst erklärte im Januar 2015 sogar, vollständig auf die ukrainischen Pipelines verzichten zu wollen.

Die neuen Pipelineprojekte - drei Unterwasserpipelines sowie zwei Überlandpipelines - sollen jegliche Transitländer umgehen. Sie werden im Folgenden kurz vorgestellt.

\section{Blue Stream}

Die Blue Stream-Pipeline von Russland durch das Schwarze Meer in die Türkei hat derzeit eine Kapazi- tät von $16 \mathrm{Mrd}$. Kubikmetern, die aber zumeist nicht ausgeschöpft wird. Trotzdem versuchte Gazprom im Jahre 2010, die Türkei zum Bau einer zweiten Röhre zu bewegen, die die Kapazität auf 30 Mrd. Kubikmeter erhöht hätte. Die Türkei lehnte diesen Vorschlag jedoch ab. Im Jahr 2015 vereinbarten beide Parteien dann aber die Erhöhung der Kapazität von 16 auf 19 Mrd. Kubikmeter pro Jahr durch eine Modernisierung der Kompressorstationen.

Bisher wird die Türkei von Gazprom mit rund 16 Mrd. Kubikmetern durch die Blue Stream-Pipeline und mit rund 14 Mrd. Kubikmetern durch die "Trans-Balkan-Pipeline« über Rumänien und Bulgarien beliefert. Gazprom scheint gehofft zu haben, mit dem neuen Projekt »Turk Stream» die Ukraine weitgehend als Transitland ersetzen zu können. Im Januar 2015 gab Gazprom dementsprechend bekannt, dass das Unternehmen von 2019 an kein Gas für den europäischen Markt mehr durch die Ukraine transportieren wolle.

\section{Turk Stream}

Die Bedeutung der Türkei, nicht nur als Abnehmerland für russisches Erdgas, sondern auch als Transitland stieg, als der russische Präsident Wladimir Putin im Dezember 2014 während seines Besuchs in Ankara den Plan zum Bau einer weiteren Unterwasserpipeline in die Türkei vorschlug. Der Vorschlag kam kurz nachdem auf Druck der EU das South Stream-Pipelineprojekt aufgegeben worden war, das von Russland durch das Schwarze Meer über den Balkan Erdgas in die EU liefern sollte, aber aus Sicht der EU gegen verschiedene Wettbewerbsregeln verstieß.

Die Turk Stream-Pipeline (auch "Turkish Stream» genannt) sollte ursprünglich mit vier Röhren eine Gesamtkapazität von 63 Mrd. Kubikmetern pro Jahr haben, von denen $14 \mathrm{Mrd}$. Kubikmeter für den türkischen Markt bestimmt waren, während die restlichen 49 Mrd. Kubikmeter über Griechenland nach Europa exportiert werden sollten. Gaslieferungen durch die erste Röhre mit einer Kapazität von 15,75 Mrd. Kubikmetern sollten bereits Ende 2016 beginnen.

Diese Terminsetzung ist sehr optimistisch, da das Projekt teuer und technisch anspruchsvoll ist. Zusätzlich 
müssten die europäischen Abnehmer den Bau einer Pipelineinfrastruktur ab der türkisch-griechischen Grenze selbst übernehmen. Die bisherige Infrastruktur ist unzureichend. Auf Druck der USA haben allerdings Serbien und Mazedonien ihre Teilnahme an dem Projekt abgesagt; sie wollen zudem ihre Gasversorgung diversifizieren und kein zusätzliches russisches Gas importieren. Ihr Ausscheiden als Abnehmerländer macht das Projekt unwahrscheinlicher, zumindest aber unwirtschaftlicher. Unterstützung für die Pipeline kam bisher lediglich aus Griechenland und Ungarn.

Der Baubeginn hat sich wiederholt verzögert. Obwohl die erste Röhre von Turk Stream vor Ende 2016 fertiggestellt werden sollte, wurde der Ausbau des internen russischen Pipelinenetzes zur Belieferung der Turk Stream-Pipeline auf Eis gelegt. Zudem wurde im Juli 2015 auch der Vertrag mit der für die Turk StreamPipeline beauftragten italienischen Pipelinebaufirma "Saipem« überraschend durch Gazprom aufgelöst.

In der von Gazprom vorgelegten Umweltverträglichkeitsprüfung spricht das Unternehmen im Juli 2015 auch nur noch von zwei Röhren mit einer Kapazität von jeweils 15,75 Mrd. Kubikmetern. Aus Unternehmenskreisen wurde verlautbart, dass die erste Röhre von Turk Stream auf jeden Fall gebaut werde. Dies wohl mit dem Ziel, zumindest die Versorgung des türkischen Marktes komplett unabhängig von der Ukraine betreiben zu können und/oder nach dem Scheitern des South StreamProjekts das Gesicht zu wahren.

Im Oktober 2015 erklärte Gazprom offiziell, dass es nur noch beabsichtige zwei Röhren mit einer Gesamtkapazität von $32 \mathrm{Mrd}$. Kubikmeter zu bauen.

Der Energieexperte Michail Kortschemkin behauptet allerdings, dass die Turk Stream-Pipeline nur ein Bluff sei, um Druck auf die Ukraine auszuüben. Dafür würde sprechen, dass Gazprom die Verträge mit dem Pipelinebauer Saipem annulliert hat und auch das heimische Pipelinenetz in Südrussland nicht weiter ausbaut.

\section{Nord Stream}

Der Ausbau der Nord Stream Pipeline um weitere Röhren wurde zu einem Zeitpunkt vorgeschlagen, als der Bau der Turk Stream Pipeline nach den Parlamentswahlen in der Türkei an Fahrt verloren hatte. Entsprechende Pläne existieren seit der Inbetriebnahme 2011, sie wurden aber noch im Januar 2015 wegen der schwierigen politischen Situation (Ukraine-Krise) und der gesunkenen europäischen Nachfrage nach russischem Gas auf Eis gelegt.

Im Juni 2015 gab Gazprom allerdings bekannt, dass es plant, zwei weitere Röhren für Nord Stream bauen zu wollen. Das würde die bisherige Kapazität von Nord Stream von 55 auf 110 Mrd. Kubikmeter ver- doppeln. Die Fertigstellung der beiden Röhren ist für 2019 geplant. Dies ist eine überraschende Entscheidung, nachdem frühere Versuche des Unternehmens für einen Ausbau der Pipeline erfolglos verliefen. Es stellen sich mit Blick aufEU-Regulierungen rechtliche Fragen sowie ökonomische hinsichtlich des europäischen Gasbedarfs: Kann und will die EU so viel russisches Gas abnehmen?

Zudem war Nord Stream 2013 mit 27 Mrd. Kubikmetern nur zur Hälfte ausgelastet, da die weiterführenden Pipelines OPAL (»Ostsee-Pipeline-Anbindungsleitung " mit einer Kapazität von 36 Mrd. Kubikmetern pro Jahr) und NEL (»Nordeuropäische Erdgasleitung» mit einer Kapazität von $20 \mathrm{Mrd}$. Kubikmetern pro Jahr) in Deutschland der EU-Regelung für den Zugang dritter Lieferanten zu Pipelines unterliegen. Demnach müssen $50 \%$ der Kapazität für Wettbewerber zur Verfügung gestellt werden. Als NEL im November 2013 in Betrieb genommen wurde, verbesserte sich die Nord StreamAuslastung 2014 auf 36 Mrd. Kubikmeter.

Aber selbst bei vollständigem Zugang zur OPALPipeline würde deren Kapazität bei der jetzt geplanten Kapazitätsverdopplung von Nord Stream nicht ausreichen. Vielmehr müsste das europäische (deutsche) Pipelinenetz ausgebaut werden, um das zusätzliche russische Gas aufzunehmen. Die EU aber will die Ukraine als Transitland erhalten. Es darf deshalb bezweifelt werden, dass die EU ihre Zugangsbeschränkungen speziell für Gazprom aussetzt und die zusätzlichen Infrastrukturprojekte genehmigt.

\section{"Power of Siberia«-Pipeline nach China}

Parallel zur Arbeit an den Problemen mit dem europäischen Absatzmarkt begann Gazprom seine Pläne für Exportpipelines nach China zu forcieren. Am 21.5.2014 unterzeichneten Russland und China nach langen Verhandlungen einen Gasliefervertrag: Ab 2018-2020 sollen über eine Laufzeit von 30 Jahren 38 Mrd. Kubikmeter russischen Erdgases pro Jahr nach China geliefert werden. Der vereinbarte Gaspreis liegt unter dem Preis, den Gazprom in Europa erzielt. Beschlossen wurde auch der Bau einer neuen Pipeline (»Power of Siberia», russ.: "Sila Sibiri«).

Die 3.000 Kilometer lange Pipeline soll bis 2020 die zwei Erdgasfelder in Ostsibirien mit der russisch-chinesischen Grenze sowie mit dem geplanten Flüssiggas-Terminal in Wladiwostok verbinden. Die komplette Fertigstellung soll 2022 erfolgen. Die ersten Gaslieferungen sollen 2018 beginnen. Die Kapazität soll zu Beginn bei $5 \mathrm{Mrd}$. Kubikmetern liegen und sukzessive auf $38 \mathrm{Mrd}$. Kubikmeter erweitert werden. Die ersten Arbeiten wurden Anfang Juni 2015 begonnen.

China bestand auf dieser ostsibirischen Route, da damit die hochindustrialisierte chinesische Küstenre- 
gion besser bedient werden kann; es sprach sich gegen die seit Jahren mit Gazprom diskutierte Altai-Route nach Nordwestchina aus.

Bisher gingen rund $97 \%$ der russischen Erdgasexporte in die Türkei und nach Europa. Zusammen mit drei Flüssiggas-Projekten, die auch auf den asiatischen Markt ausgerichtet wären, könnten sich Russlands Gasexporte in diese Region 2020-25 auf rund 85 Mrd. Kubikmeter belaufen oder rund $27 \%$ aller Gasexporte. Dies würde für Gazprom eine Diversifizierung der Absatzmärkte bedeuten, auch bezüglich der Förderstätten, die für die neue Pipeline nach China in Ostsibirien liegen.

Trotz der Diversifizierung kann die ostsibirische Route nicht gegen den europäischen Markt ausgespielt werden, da auch die entsprechenden Fördergebiete vollständig getrennt sind. Westsibirisches Erdgas kann nicht nach Asien umgeleitet werden, da die benötigte Pipelineinfrastruktur fehlt. Die Frage wird nun sein, ob Gazprom die Finanzkraft besitzt, die Infrastruktur in Ostsibirien zu bauen.

\section{Altai-Pipeline}

Im Mai 2015 ist zusätzlich ein Abkommen über den Bau einer westlichen Gaspipeline nach China durch das Altaigebirge unterzeichnet worden, die 2020 ihren Betrieb aufnehmen soll. Die Altai-Pipeline soll eine Kapazität von $30 \mathrm{Mrd}$. Kubikmetern pro Jahr haben, die durch eine zweite und dritte Röhre bis auf $100 \mathrm{Mrd}$. Kubikmeter erhöht werden könnte.

Die Produktion des Bowanenkowo-Gasfeldes auf der Jamal-Halbinsel, auf dem seit 2012 gefördert wird, das aber aufgrund mangelnder Nachfrage in Europa nicht ausgelastet ist, ist für den Export durch die Altai-Pipeline vorgesehen. Damit würde eine wirkliche Diversifizierung des Absatzmarktes erreicht, weil Erdgas, das bisher nur auf dem europäischen Markt verkauft werden konnte, nun auch in China vermarktet werden könnte. Allerdings sind die Mengen, die dem europäischen Markt "entzogen « werden könnten, auf absehbare Zeit recht gering. Im Oktober 2015 fehlte außerdem noch ein letztverbindliches Abkommen für die Altai-Pipeline.

\section{Schlussfolgerungen}

Erdgasexporte nach Europa sind nach wie vor die Haupteinnahmequelle für Gazprom. Von daher bemüht sich das Unternehmen auch weiterhin, sich von Transitländern unabhängig zu machen. Die Pipelineprojekte des Unternehmens sind dabei von strategischen Überlegungen geprägt und vernachlässigen wirtschaftliche, technische und rechtliche Aspekte oftmals.

Der geplante Ausbau der Nord Stream-Pipeline macht einen gleichzeitigen Ausbau des deutschen Pipelinenetzes erforderlich, um das Gas zum Abnehmer zu bringen. Bereits jetzt können vorhandene Kapazitäten aufgrund von EU-Regelungen nicht voll genutzt werden.

Aufgrund der fehlenden Pipelineinfrastruktur auf dem Balkan ist die Turk Stream-Pipeline für eine Versorgung des europäischen Marktes keine sehr realistische Lösung; eine Versorgung der Türkei allein durch Unterwasserpipelines erscheint möglich, ist aber teuer.

Zumindest aber üben beide Pipelineprojekte Druck auf die Ukraine aus und stärkt Gazproms Verhandlungsposition. Das Unternehmen scheint in Zukunft auf kurzfristige Transitverträge mit der Ukraine zu setzen, die mit Hilfe der EU ausgehandelt und von ihr "garantiert" werden. Zudem ist der Anteil der Ukraine am Gastransit bereits zurückgegangen; nur noch rund $50 \%$ der russischen Erdgasexporte nach Europa und in die Türkei fließen durch das Land. 1995 waren es 95\%, 2005 immerhin noch 75\%. Ein völliges Ausscheiden der Ukraine als Transitland ist aber nicht abzusehen.

Die Überlandpipelines nach China sind weniger problembeladen, auch wenn Gazprom große Investitionen tätigen muss und auf dem chinesischen Markt nur geringere Gewinne machen kann. Die Diversifizierung nach China könnte nur dann eine Bedrohung für die Marktmacht Europas als Abnehmer darstellen, wenn sie über die Altai-Pipeline erfolgt, was in ferner Zukunft liegt. Die Power of Siberia-Pipeline hingegen stellt keine Bedrohung dar, da über sie keine Gasmengen vom europäischen Markt umgeleitet werden können.

\section{Über den Autor}

Dr. Andreas Heinrich ist Experte für die Energiepolitik in der ehemaligen Sowjetunion und arbeitete bis August 2015 an der Forschungsstelle Osteuropa an der Universität Bremen. Er ist dort derzeit assoziierter Wissenschaftler im Rahmen des Forschungsprojektes »Auf dem Weg zu einer gemeinsamen europäischen Energiepolitik? Energiesicherheitsdebatten in Polen und Deutschland«, das aus Mitteln der Deutsch-Polnischen Wissenschaftsstiftung gefördert wird.

\section{Lesetipps}

- Heinrich, Andreas: Introduction: Export pipelines in Eurasia, in: Andreas Heinrich, Heiko Pleines (Hg.): Export pipelines from the CIS region. Geopolitics, securitization, and political decision-making [= Changing Europe, Bd. 10], Stuttgart: ibidem, 2014, S. 1-73. 
- Kardaś, Szymon, Agata Łoskot-Strachota, Konrad Popławski: Gas business as usual? The new agreements between Gazprom and EU energy companies. Warschau: Ośrodek Studiów Wschodnich, 09. 09. 2015; <http://www.osw. waw.pl/en/publikacje/analyses/2015-09-09/gas-business-usual-new-agreements-between-gazprom-and-eu-energy>.

- Martinez, Miguel, Martin Paletar, Harald Hecking: The 2014 Ukrainian crisis. Europe's increased security position: Natural gas network assessment and scenario simulations. Köln: Energiewirtschaftliches Institut an der Universität zu Köln (EWI), 19. März 2015, <http://www.ewi.uni-koeln.de/fileadmin/user_upload/Publikationen/Stu dien/Politik_und_Gesellschaft/2015/Ukrainian_crisis_Europes_increased_security_position_final.pdf >.

- Willershausen, Florian: Kein »Game-Changer« für Europas Energiesicherheit. Russlands Gas-Deal mit China und seine Folgen. Berlin: Friedrich-Ebert-Stiftung (FES), Juli 2014, <http://library.fes.de/pdf-files/id-moe/10852.pdf>.

\section{ANALYSE}

\section{Gazproms neue Strategie für Europa}

Julia Kusznir, Bremen

\section{Zusammenfassung}

Der Artikel analysiert die aktuellen Vereinbarungen von Gazprom bezüglich der neuen Erdgaspipelines „Nord Stream 2« und »Turk Stream» im Kontext der europäischen Energieversorgung. Falls die neuen Pipelines gebaut werden, könnten sie alternative Versorgungswege verdrängen. Einerseits wird damit Russlands Position als zentraler Erdgasversorger der EU gestärkt, andererseits zeigt Russland dadurch, dass es weiterhin auf den europäischen Markt angewiesen ist. Bei der Durchsetzung der neuen Strategie für Europa nutzt Gazprom mit Geschick die politische Schwäche der EU in Energiefragen und stellt dadurch die europäische Solidarität im Bereich der Energiesicherheit infrage.

\section{Einleitung}

Anfang September diesen Jahres hat der russische Staatskonzern Gazprom im Rahmen des Östlichen Wirtschaftsforums in Wladiwostok eine Reihe von Energieabkommen mit westeuropäischen Energiekonzernen unterzeichnet, darunter eine Vereinbarung zum Bau der Pipeline »Nord Stream 2« mit einer jährlichen Kapazität von 55 Mrd. Kubikmeter Gas. Die Pipeline soll ergänzend zur 2011 in Betrieb genommenen ersten Nord Stream-Pipeline russisches Gas durch die Ostsee nach Deutschland und über das deutsche Gasnetz in weitere EU-Länder transportieren. Mit dem Projekt würde sich die Kapazität von Nord Stream verdoppeln. Am Projekt soll Gazprom 51 \% der Anteile halten und weitere vier westliche Partner (die deutschen Unternehmen »E.On« und "Wintershall«, die britisch-holländische "Shell« und die österreichische OMV) sollen je $10 \%$, und die französische »Engie« $9 \%$ der Anteile halten. Da die Pipeline an der Ukraine vorbeiführen würde, würde die Bedeutung der Ukraine als Transitland deutlich reduziert und Deutschlands Rolle als Transitland und als größter Gasverteiler in Europa gestärkt.

Dies erscheint angesichts der Ukraine-Krise und der Blockade von Gazproms South Stream-Projekt durch die EU, einer Erdgaspipeline über den Balkan in die EU, als logischer Schritt der russischen Exportpolitik. Die Nord Stream 2-Pipeline wird von vielen Experten als Triumph der langjährigen deutsch-russischen Energiekooperation gesehen.

\section{Kritik in der EU}

Bei den mittel- und südosteuropäischen Ländern hat die neue Vereinbarung über Nord Stream 2 allerdings für Empörung gesorgt. Polen kritisierte nachdrücklich, dass das Abkommen ohne Absprache mit der polnischen Regierung zustande kam, und dass die neue Ostseepipeline zukünftig die polnische Energiesicherheit gefährden kann. Die EU-Länder Bulgarien und Ungarn können enttäuscht sein. Beide Länder waren Partner von Gazprom im South Stream-Projekt und hatten auf direkte Erdgaslieferungen und Einnahmen aus den Transitpipelines gehofft. Die EU-Kommission entschied aber, dass Baugenehmigungen für die Pipeline auf bulgarischem Territorium nicht im Einklang mit EU-Recht erteilt wurden und drohte mit einem rechtlichen Verfahren. Aus diesem Grund musste Bulgarien die Bauarbeiten an South Stream im Juni 2014 stoppen. Jetzt profitieren vor allem Deutschland und Tschechien vom russischen Pipelineprojekt. 
Die EU-Kommission, die schon das South StreamProjekt an den Wettbewerbungsbestimmungen zur Liberalisierung des Erdgasmarktes hatte scheitern lassen, stellt auch für das Nord Stream-Projekt ein großes Problem dar. Hauptziel der EU Kommission ist die Entflechtung von Erzeugung und Versorgung auf dem europäischen Gasmarkt. Dementsprechend müssen Pipeline-Betreiber dritten Anbietern Pipelinekapazität überlassen, sofern die Europäische Kommission und die betreffende nationale Regulierungsbehörden keine Ausnahme erlauben. Da Nord Stream und die Anschlusspipelines innerhalb der EU von Gazprom kontrolliert werden, kann russisches Gas ohne explizite Genehmigung deshalb nicht in voller Kapazität durch die Pipelines strömen. Die Europäische Kommission hat aber bisher kein großes Interesse an Nord Stream 2 gezeigt, mit der Begründung, dass eine neue Pipeline in Umgehung der Ukraine nicht gebraucht werde.

\section{Gazproms Reaktionen}

Einige Experten sehen hinter dem Nord Stream-Deal weniger wirtschaftliche und energiepolitische Interessen als vielmehr finanzielle Interessen der beteiligten Firmen. Nach Angaben von Michail Krutichin, Energieexperte und Partner bei der Consulting-Firma »RusEnergy«, bietet das Abkommen den beteiligen ausländischen Investoren lukrative Einnahmen in Form von Transportgebühren unabhängig davon, ob und wieviel Gas über die Pipeline transportiert wird. Da 51\% der Anteile an Nord Stream einer Tochtergesellschaft von Gazprom gehören, die in der Schweiz registriert ist, werden diese Einnahmen nicht in Russland versteuert und nicht in den russischen Staatshaushalt fließen.

Gazprom hat jedoch, wenn auch zögerlich, mit einer neuen Strategie auf die Herausforderungen auf dem europäischen Absatzmarkt reagiert. Nord Stream2 kann dahingehend interpretiert werden, dass anstatt einer individuellen Belieferung der einzelnen nationalen Märkte Gazprom jetzt den gesamten europäischen Energiemarkt - ganz im Sinne der europäischen Kommission - als einen Abnehmer betrachtet, der vorrangig über eine direkte Pipelineroute, nämlich die ausgebaute Nord Stream-Pipeline durch die Ostsee beliefert wird und damit gleichzeitig Transitländer vermeidet.

Um sich mit den Wettbewerbsbestimmungen der EU für den Erdgasmarkt zu arrangieren, hat sich Russland in den letzten Jahren zunehmend bereit gezeigt, den eigenen nationalen Erdgasmarkt zu liberalisieren. Grundlage hierfür ist die Betonung der Gegenseitigkeit in den EU-Regeln, die nur denjenigen ausländischen Firmen unbegrenzten Marktzugang erlauben will, bei denen auch auf ihrem Heimatmarkt EU-konforme Wettbewerbsregeln gelten.
Die russische Regierung hat Schritte unternommen, die Gazproms Kontrolle über das gesamte russische Pipelinenetz für Erdgas und das gesetzlich festgeschriebene Monopol auf Gasexporte lockern sollen. Mit einem Gesetz, das im Dezember 2013 in Kraft trat, wurde anderen russischen Gasproduzenten bereits der Export von Flüssiggas erlaubt, der über Tanker und nicht über Pipelines erfolgt. Derzeit werden Regelungen diskutiert, die anderen Unternehmen auch Zugang zu den Exportpipelines gewähren sollen. Auf Betreiben von Igor Setschin, Leiter des staatlichen Energiekonzerns "Rosneft" und ein enger Vertrauter von Präsident Putin, hat der russische föderale Antimonopoldienst eine Anfrage an die präsidiale Kommission für den Energiesektor vorbereitet, die eine Ausgliederung des Pipelinenetzes in ein eigenes Unternehmen fordert. Damit wäre Gazprom nicht mehr der Betreiber von Nord Stream und den Anschlusspipelines und könnte als vom Pipelinebetreiber formal unabhängiger Produzent die volle Kapazität nutzen. Derzeit ist noch unklar, ob Präsident Putin diese Pläne unterstützen wird. Laut russischen Medienberichten soll in Kürze eine Entscheidung getroffen werden.

Auf Grund der wirtschaftlichen Stagnation wird davon ausgegangen, dass die Gasnachfrage in Russland selbst in den folgenden Jahren nicht steigen wird. Daher wächst für Gazprom die Bedeutung der Gasexporte erheblich. Der Konzern bemüht sich deshalb, über das "Turk Stream«-Projekt auch die Exporte in die Türkei und nach Südeuropa zu erhöhen sowie über zwei weitere Pipelineprojekte Zugang zum chinesischen Markt zu erhalten. Auch hier gibt es aber erhebliche Probleme bei der Umsetzung, wie der obige Beitrag von Andreas Heinrich erläutert.

\section{Resümee}

Die Liberalisierung des europäischen Erdgasmarktes durch die EU-Kommission, die westlichen Sanktionen gegen Russland in Folge der Ukrainekrise sowie die Stagnation der Gasnachfrage auf dem russischen Binnenmarkt führten dazu, dass der Kreml seine bisherigen Energiestrategien überdenken musste. Er versucht sich mit Flexibilität an die herrschende Realität anzupassen, die Schwächen der politischen Händel der EU in Energiefragen auszunutzen und tut dies in gewissem Grade mit Erfolg.

Mit dem Stopp für das South Stream-Projekt entstand der Eindruck, dass Gazprom sich von Investitionen in den europäischen Absatzmarkt verabschiedet hat. Dagegen setzt Russland nun auf eine neue Strategie, die auf den zwei Pipelineprojekten Nord Stream 2 und Turk Stream basiert. Mit zusätzlichen Exportkapazitäten sollen Versorgungsalternativen für Deutschland und die mittelosteuropäischen EU-Mitgliedsstaaten ver- 
drängt und damit Gazproms Position als Hauptlieferant gestärkt werden.

Gleichzeitig versucht Russland zur Stärkung seiner Position auf den europäischen Märkten sich an die EU-Vorschriften anzupassen und dies entweder direkt durch Verhandlungen mit Brüssel oder indirekt durch bilaterale Abkommen mit westlichen Unternehmen zu erreichen. Inwieweit dabei der Forderung der EU nach einer Liberalisierung des russischen Binnenmarktes für Erdgas nachgekommen wird, bleibt jedoch abzuwarten.

Obwohl im rechtlichen Bereich die Beziehungen zwischen Russland und der EU in letzter Zeit unverändert blieben, ändern sich die Einstellungen der Akteure im Bereich der Energiekooperation. Nord Stream 2 hat höhere Chancen auf eine schnellere Realisierung als Turk Stream, weil die Unterstützung von allen im Projekt beteiligten Partnern, darunter auch Deutschlands, gesichert ist. Die Realisierung dieser politisch motivierten Projekte könnte allerdings mehrere Jahre in Anspruch nehmen, da die Krisen in der Ukraine und in Syrien die Verhandlungen überschatten.

Russlands Gasexporte müssen dabei im Zusammenhang mit der gegenwärtigen schwachen Wirtschaftslage Russlands, mit der einseitigen Ausrichtung der russischen Wirtschaft auf Erdöl- und Erdgaseinnahmen und den mangelnden Investitionen in die Exploration von neuen Erdgasfeldern betrachtet werden. Ohne westliche Investitionen können diese Probleme nicht bewältigt werden. Russland ist weiterhin auf den europäischen Markt angewiesen und die Abhängigkeit auf beiden Seiten bleibt kurz- und mittelfristig bestehen.

Nord Stream stellt allerdings - sowohl mit dem ursprünglichen Projekt als auch jetzt mit Nord Stream 2 die europäische Solidarität im Bereich der Energiesicherheit in Frage. Während die größten europäischen Energiekonzerne, die an Nord Stream 2 beteiligt sind, das Projekt unterstützen, äußern Brüssel und die mittelosteuropäischen Länder starke Kritik und lehnen das Projekt ab. Deshalb ist damit zu rechnen, dass die mittelosteuropäischen Länder zukünftig noch stärker auf ihre eigenen nationalen Interessen setzen werden, und dass das Vertrauen in eine gemeinsame EU-Politik sinken wird. Damit könnte sich die Spaltung in Europa bei
Fragen der Energieversorgung weiter vertiefen, was die Pläne zur Schaffung einer europäischen Energieunion wesentlich belasten könnte.

Wenn Nord Stream 2 und Turk Stream wie geplant in Betrieb genommen würden, würde Russland sich von einem Gastransit durch die Ukraine völlig abkoppeln. Da allerdings die neuen Pipelineprojekte mit vielen Problemen konfrontiert sind und außerdem innerhalb der EU die Infrastruktur (Gasinterkonnektoren) für die Weiterleitung an alle Abnehmer fehlt, ist der Verzicht auf ukrainische Transitpipelines bis 2019 kaum realisierbar. Für die von Gazprom geplante Ausweitung der Exporte nach Mittelosteuropa und auf den Balkan bleiben außerdem die ukrainischen Transitpipelines in die Slowakei von großer Bedeutung, weil sie in Ergänzung zu Nord Stream und Turk Stream, die jeweils nur den nördlichen bzw. südlichen Teil des europäischen Marktes beliefern, längerfristig eine Flexibilität bei russischen Erdgaslieferungen in die EU erlauben würden. Deshalb ist davon auszugehen, dass Gazprom die Ukraine auch langfristig als Transitroute nutzen wird, wenn auch - im Falle einer Realisierung alternativer Exportpipelines - in reduziertem Umfang.

Gazproms Aktivitäten im Kaspischen Raum und in den Verhandlungen mit China zeigen, dass Russland seine Position verstärkt auf anderen regionalen Energiemärkten auszubauen sucht, auch wenn dies mit hohen politischen und wirtschaftlichen Kosten verbunden ist. Es ist noch zu früh für eine Einschätzung, inwiefern oder ob diese Politik erfolgreich ist. Die Realisierung der Projekte hängt stark von anderen Faktoren ab, wie etwa der Entwicklung der Weltmarktpreise für Erdöl, geopolitischen Entwicklungen in den betroffenen Regionen und der Bereitschaft der an den Projekten beteiligten Länder, den russischen Interessen entgegenzukommen.

Allerdings kann auch konstatiert werden, dass Russlands Energiepolitik zunehmend komplexer und weniger vorhersehbar ist, weil neue Akteure mit ihren eigenen Unternehmensstrategien und persönlichen Interessen in die russischen Gasexporte einsteigen. Dies wird die Aktivitäten der russischen Erdgaswirtschaft zukünftig sowohl intern als auch extern stark beeinflussen.

\section{Über die Autorin}

Dr. Julia Kusznir hat als Energieexpertin an der Jacobs University in Bremen gearbeitet, zuletzt als wissenschaftliche Mitarbeiterin im laufenden Forschungsprojekt "Auf dem Weg zu einer gemeinsamen europäischen Energiepolitik? Energiesicherheitsdebatten in Polen und Deutschland«, das aus Mitteln der Deutsch-Polnischen Wissenschaftsstiftung gefördert wird. 


\section{Russische Erdgasexporte: Umfang, Pipelines, Abnehmerländer}

Grafik 1: Gazproms Erdgasproduktion und -exporte (in Mrd. Kubikmetern)

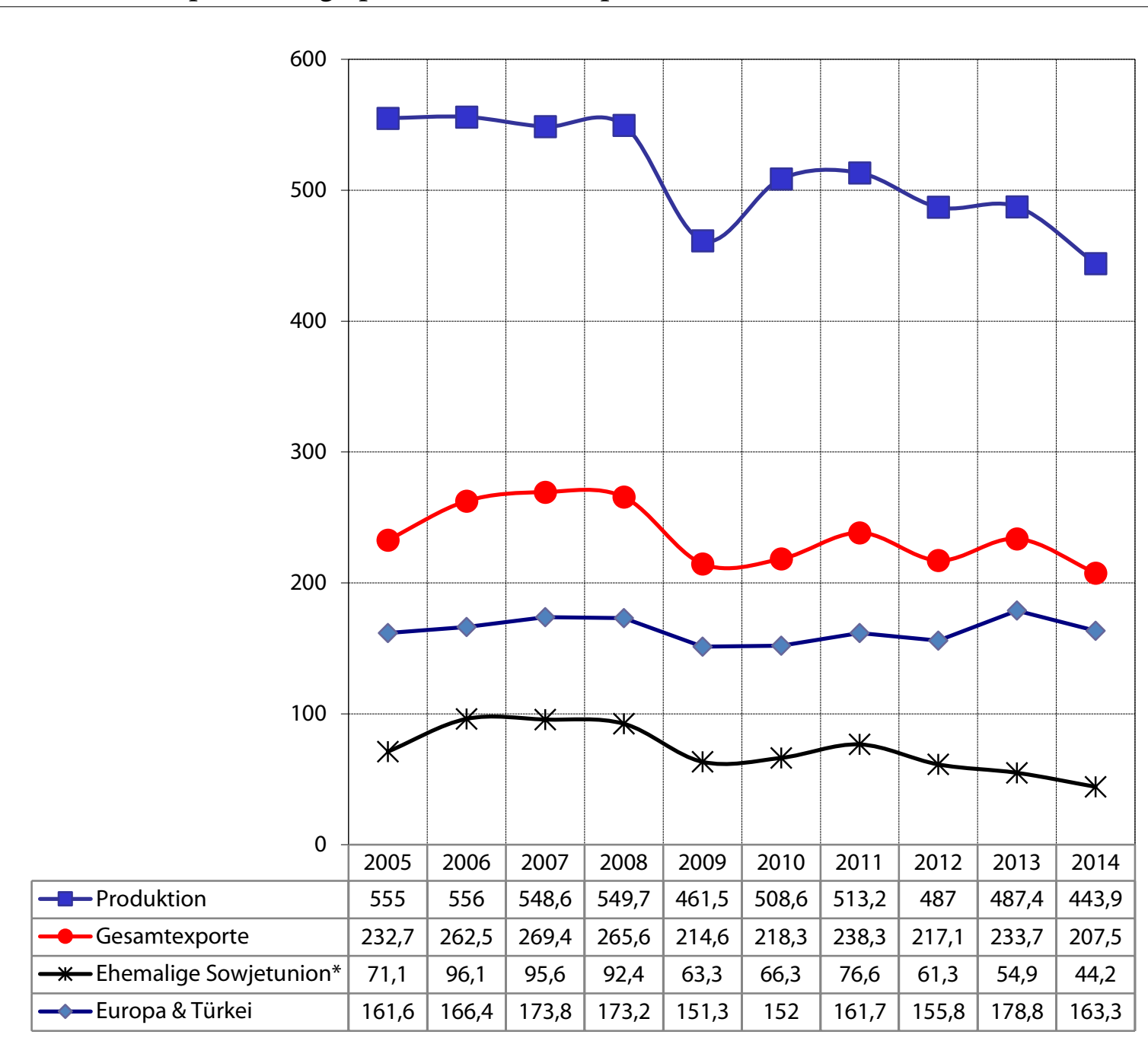

* Die baltischen Staaten wurden entgegen der Praxis von Gazprom unter Europa und nicht unter Ehemalige Sowjetunion erfasst. Quelle: Gazprom Unternehmensangaben; eigene Berechnungen 
Tabelle 1: Russlands Erdgasexportrouten (Pipelinekapazität in Mrd. Kubikmeter pro Jahr)

\begin{tabular}{|c|c|c|c|}
\hline Pipeline & Route & Kapazität 2015 & $\begin{array}{l}\text { Kapazität } 2020 \\
\quad \text { (geplant) }\end{array}$ \\
\hline Bruderschaft (Sowjetisches Pipelinenetz) & $\begin{array}{l}\text { Russland - Ukraine - } \\
\text { Mitteleuropa }\end{array}$ & 100 & 100 \\
\hline Nordlicht (Sowjetisches Pipelinenetz) & $\begin{array}{l}\text { Russland - Belarus - } \\
\text { Ukraine - Mitteleuropa }\end{array}$ & 55 & 55 \\
\hline Trans-Balkan (Sowjetisches Pipelinenetz) & $\begin{array}{l}\text { Russland - Ukraine - } \\
\text { Balkan - Türkei }\end{array}$ & 28 & 28 \\
\hline $\begin{array}{l}\text { Finland Connector (Sowjetisches } \\
\text { Pipelinenetz, ausgebaut 1999) }\end{array}$ & Russland - Finnland & 20 & 20 \\
\hline Jamal-Europa (seit 1999 in Betrieb) & $\begin{array}{l}\text { Russland - Belarus - } \\
\text { Polen - Westeuropa }\end{array}$ & 34 & 34 \\
\hline Blue Stream (seit 2005 in Betrieb) & $\begin{array}{l}\text { Russland - Schwarzes } \\
\text { Meer - Türkei }\end{array}$ & 16 & 19 \\
\hline Nord Stream (seit 2011 in Betrieb) & $\begin{array}{l}\text { Russland - Ostsee - } \\
\text { Deutschland }\end{array}$ & 55 & 110 \\
\hline $\begin{array}{l}\text { Power of Siberia (Inbetriebnahme geplant } \\
\text { für 2018) }\end{array}$ & Russland - China & - & 38 \\
\hline $\begin{array}{l}\text { Altai Pipeline (Inbetriebnahme geplant für } \\
\text { 2020) }\end{array}$ & Russland - China & - & 30 \\
\hline $\begin{array}{l}\text { Turk Stream (Inbetriebnahme geplant für } \\
\text { 2016) }\end{array}$ & $\begin{array}{l}\text { Russland - Schwarzes } \\
\text { Meer - Türkei }\end{array}$ & - & 31,5 \\
\hline Gesamtkapazität & & 308 & 465,5 \\
\hline
\end{tabular}

Quelle: Heinrich, Andreas: Introduction: Export pipelines in Eurasia, in Heinrich, Andreas/ Pleines, Heiko (eds) Export pipelines from the CIS region: Geopolitics, securitization, and political decision-making. Stuttgart: ibidem, 2014, 1-73, eigene Zusammenstellung.

\section{Grafik 2: Regionale Verteilung von Gazproms Erdgasexporten 2012 und 2014}

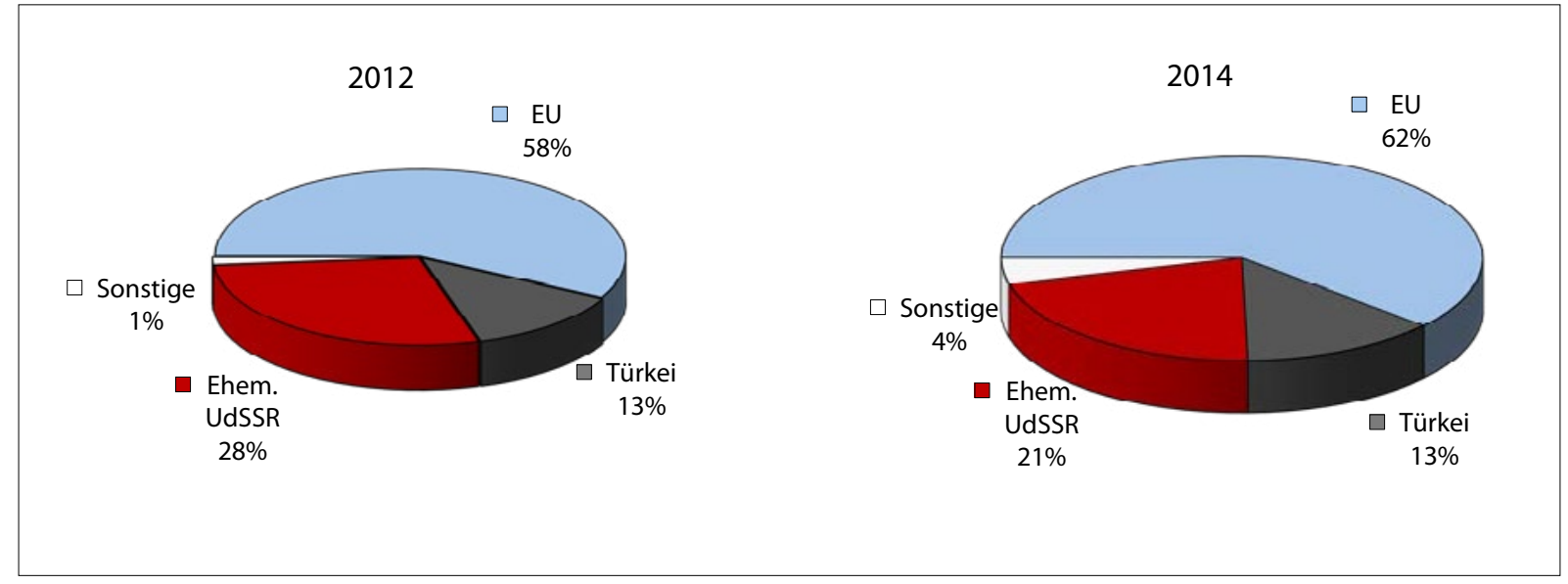

Quelle: Gazprom Unternehmensangaben; eigene Berechnungen 
Grafik 3: Die größten Abnehmerländer von Gazproms Erdgasexporten 2012 und 2014 (in Mrd. Kubikmetern)

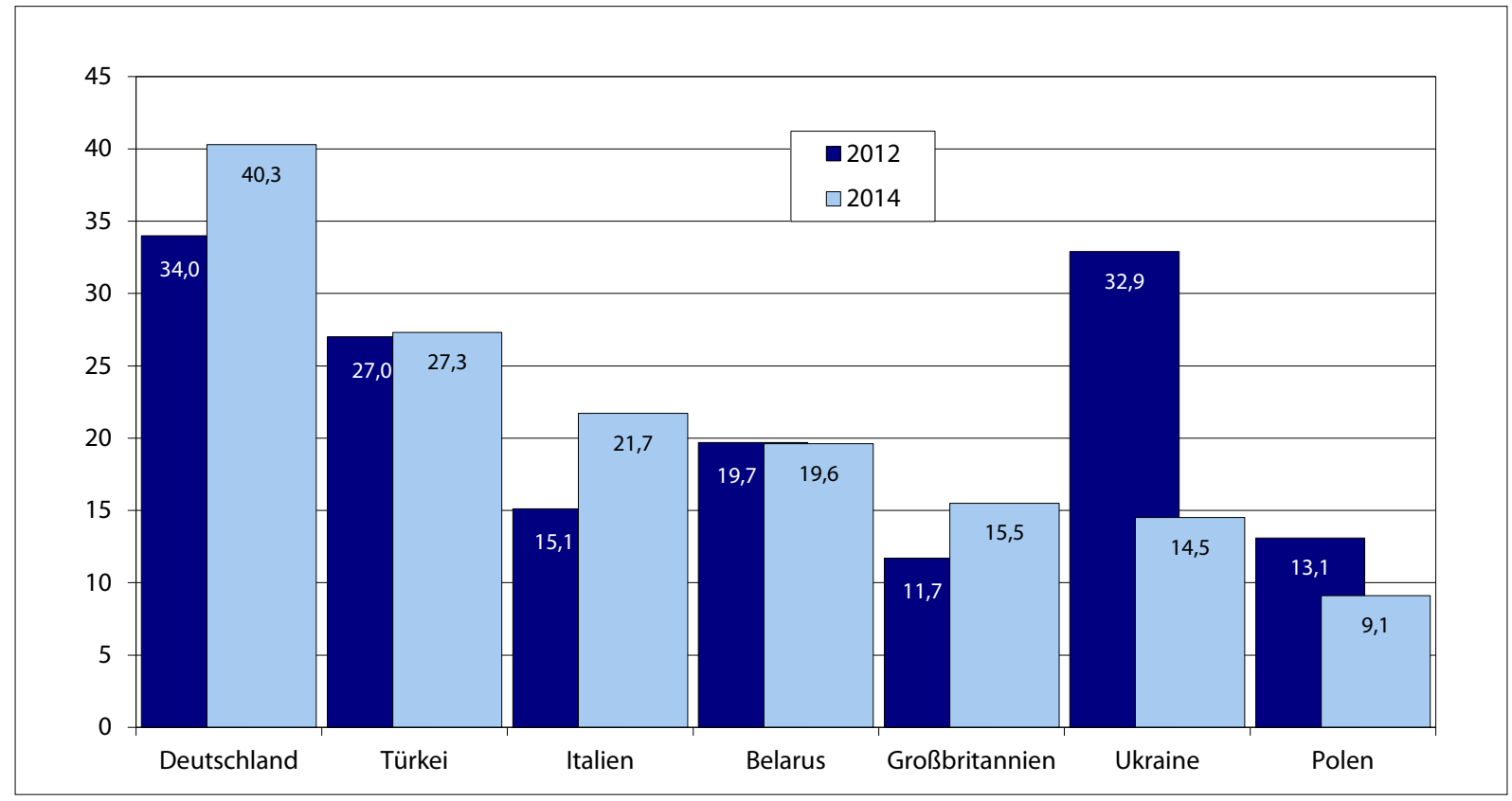

Quelle: Gazprom Unternehmensangaben; eigene Berechnungen

Tabelle 2: Gazproms Erdgasexporte nach Abnehmerländern (in Mrd. Kubikmetern)

\begin{tabular}{|c|c|c|c|c|c|c|c|c|c|c|c|}
\hline \multirow{2}{*}{\multicolumn{2}{|c|}{ Fernes Ausland }} & 2005 & 2006 & 2007 & 2008 & 2009 & 2010 & 2011 & 2012 & 2013 & 2014 \\
\hline & & & & & & & & & & & \\
\hline \multirow[t]{22}{*}{ EU-28 } & Belgien & 2 & 3,2 & 4,3 & 4,9 & 0,5 & 0,5 & - & - & - & - \\
\hline & Bulgarien & 2,6 & 2,7 & 2,8 & 2,9 & 2,2 & 2,3 & 2,5 & 2,5 & 2,9 & 2,8 \\
\hline & Dänemark & - & - & - & - & - & - & - & 0,3 & 0,3 & 0,4 \\
\hline & Deutschland & 36 & 34,4 & 34,5 & 37,9 & 33,5 & 35,3 & 34,1 & 34 & 41 & 40,3 \\
\hline & Estland & 1,3 & 0,7 & 0,9 & 0,6 & 0,8 & 0,4 & 0,7 & 0,6 & 0,7 & 0,4 \\
\hline & Finnland & 4,5 & 4,9 & 4,7 & 4,8 & 4,4 & 4,8 & 4,2 & 3,7 & 3,5 & 3,1 \\
\hline & Frankreich & 13,2 & 10 & 10,1 & 10,4 & 8,3 & 8,9 & 8,5 & 8,2 & 8,6 & 7,6 \\
\hline & Griechenland & 2,4 & 2,7 & 3,1 & 2,8 & 2,1 & 2,1 & 2,9 & 2,5 & 2,6 & 1,7 \\
\hline & Großbritannien & 3,8 & 8,7 & 15,2 & 7,7 & 9,7 & 10,7 & 12,9 & 11,7 & 16,6 & 15,5 \\
\hline & Irland & - & - & - & - & - & - & - & 0,3 & 0,5 & 0,2 \\
\hline & Italien & 22 & 22,1 & 22 & 22,4 & 19,1 & 13,1 & 17,1 & 15,1 & 25,3 & 21,7 \\
\hline & Kroatien & 1,2 & 1,1 & 1,1 & 1,2 & 1,1 & 1,1 & - & - & 0,2 & 0,6 \\
\hline & Lettland & 1,4 & 1,4 & 1 & 0,7 & 1,1 & 0,7 & 1,2 & 1,1 & 1,1 & 1 \\
\hline & Litauen & 2,8 & 2,8 & 3,4 & 2,8 & 2,5 & 2,8 & 3,2 & 3,1 & 2,7 & 2,5 \\
\hline & Niederlande & 4,1 & 4,7 & 5,5 & 5,3 & 5,1 & 4,3 & 4,5 & 2,9 & 2,9 & 4,7 \\
\hline & Österreich & 6,8 & 6,6 & 5,4 & 5,8 & 5,4 & 5,6 & 5,4 & 5,4 & 5,2 & 4,2 \\
\hline & Polen & 7 & 7,7 & 7 & 7,9 & 9 & 11,8 & 10,3 & 13,1 & 12,9 & 9,1 \\
\hline & Rumänien & 5 & 5,5 & 4,5 & 4,2 & 2,5 & 2,6 & 3,2 & 2,5 & 1,4 & 0,5 \\
\hline & Slowakei & 7,5 & 7 & 6,2 & 6,2 & 5,4 & 5,8 & 5,9 & 4,3 & 5,5 & 4,4 \\
\hline & Slowenien & 0,7 & 0,7 & 0,6 & 0,6 & 0,5 & 0,5 & 0,5 & 0,5 & 0,5 & 0,4 \\
\hline & Tschechien & 7,4 & 7,4 & 7,2 & 7,9 & 7 & 9 & 8,2 & 8,3 & 7,9 & 0,8 \\
\hline & Ungarn & 9 & 8,8 & 7,5 & 8,9 & 7,6 & 6,9 & 6,3 & 5,3 & 6 & 5,4 \\
\hline \multicolumn{2}{|c|}{ Summe EU-28 } & 140,7 & 143,1 & 147 & 145,9 & 127,8 & 129,2 & 131,6 & 125,4 & 148,3 & 127,3 \\
\hline
\end{tabular}


Tabelle 2: Gazproms Erdgasexporte nach Abnehmerländern (in Mrd. Kubikmetern) (Fortsetzung)

\begin{tabular}{|l|l|r|r|r|r|r|r|r|r|r|r|}
\hline \multicolumn{2}{|l|}{} & $\mathbf{2 0 0 5}$ & $\mathbf{2 0 0 6}$ & $\mathbf{2 0 0 7}$ & $\mathbf{2 0 0 8}$ & $\mathbf{2 0 0 9}$ & $\mathbf{2 0 1 0}$ & $\mathbf{2 0 1 1}$ & $\mathbf{2 0 1 2}$ & $\mathbf{2 0 1 3}$ & $\mathbf{2 0 1 4}$ \\
\hline $\begin{array}{l}\text { Restliches } \\
\text { Europa }\end{array}$ & $\begin{array}{l}\text { Bosnien/ } \\
\text { Herzegowina }\end{array}$ & 0,4 & 0,4 & 0,3 & 0,3 & 0,2 & 0,2 & 0,3 & 0,3 & 0,2 & 0,2 \\
\hline & Mazedonien & 0,1 & 0,1 & 0,1 & 0,1 & 0,1 & 0,1 & 0,1 & 0,1 & - & 0,1 \\
\hline & Schweiz & 0,4 & 0,4 & 0,4 & 0,3 & 0,3 & 0,3 & 0,3 & 0,3 & 0,4 & 0,3 \\
\hline & Serbien & 2 & 2,1 & 2,1 & 2,2 & 1,7 & 2,1 & 2,1 & 1,9 & 2 & 1,5 \\
\hline & Türkei & 18 & 19,9 & 23,4 & 23,8 & 20 & 18 & 26 & 27 & 26,7 & 27,3 \\
\hline & Andere Länder & - & 0,4 & 0,5 & 0,6 & 1,2 & 2,1 & 1,3 & 0,8 & 1,2 & 6,6 \\
\hline
\end{tabular}

Ehemalige Sowjetunion*

\begin{tabular}{|l|l|r|r|r|r|r|r|r|r|r|r|}
\hline & Armenien & 1,7 & 1,7 & 1,9 & 2,1 & 1,7 & 1,4 & 1,6 & 1,7 & 1,7 & 1,8 \\
\hline & Aserbaidschan & 3,8 & 4 & - & - & - & - & & & & \\
\hline & Belarus & 19,8 & 20,5 & 20,6 & 21,1 & 17,6 & 21,6 & 23,3 & 19,7 & 19,8 & 19,6 \\
\hline & Georgien & 1,4 & 1,9 & 1,2 & 0,7 & 0,1 & 0,2 & 0,2 & 0,2 & 0,2 & 0,3 \\
\hline & Kasachstan & 4 & 6,5 & 10 & 9,6 & 3,1 & 3,4 & 3,3 & 3,7 & 4,7 & 5,1 \\
\hline & Kirgisien & - & - & - & - & - & - & - & - & - & 0,1 \\
\hline & Moldawien & 2,8 & 2,5 & 2,7 & 2,7 & 3 & 3,2 & 3,1 & 3,1 & 2,4 & 2,8 \\
\hline & Ukraine & 37,6 & 59 & 59,2 & 56,2 & 37,8 & 36,5 & 44,8 & 32,9 & 25,8 & 14,5 \\
\hline & Usbekistan & - & - & - & - & - & - & 0,3 & - & 0,3 & - \\
\hline
\end{tabular}

Anmerkung: * Die baltischen Staaten wurden entgegen der Praxis von Gazprom unter Europa und nicht unter Ehemalige Sowjetunion erfasst.

Quelle: Gazprom Unternehmensangaben; eigene Berechnungen

Grafik 4: Wie stehen Sie zu der Entscheidung Gazproms, der Ukraine Gas zu einem erheblich ermäßigten Preis zu liefern? (Sept. 2015)

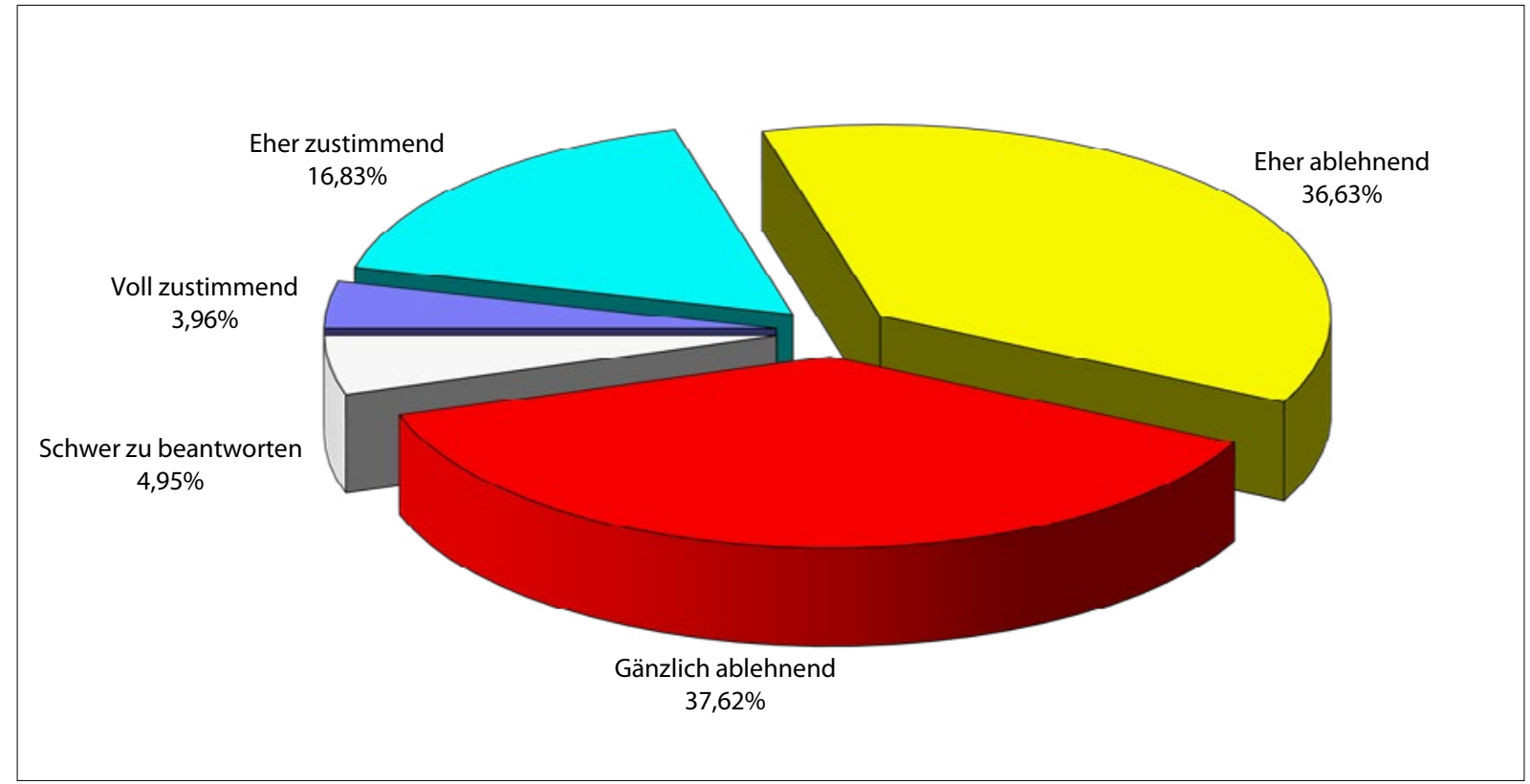

Quelle: Umfrage des Lewada-Zentrums im Zeitraum vom 2.-5. Oktober 2015, $N=800<$ http://www.levada.ru/print/15-10-2015/po litika-rossii-v-otnoshenii-ukrainy>, 15. Oktober 2015 


\section{Wirtschaftskrise in Russland - und keiner protestiert. Warum?}

Jens Siegert, Moskau

$\mathrm{D}$ ie Wirtschaftskrise in Russland dauert nun schon, mit kleineren Aufs und größeren Abs, mehr als sechs Jahre. Ein Ende ist nicht in Sicht. Die politische Führung verspricht zwar und immer wieder baldige Besserung (was sollte sie auch sonst tun?). Doch selbst Präsident Putin (der sich eher selten in die Niederungen der Wirtschaftspolitik herablässt), sprach Mitte Oktober auf einem Wirtschaftsforum davon, dass zwar "der Höhepunkt der Krise erreicht" sei, die Wirtschaft "sich an die veränderten Bedingungen angepasst" habe und sich die Situation stabilisiere, es aber »in vielen Sektoren der Wirtschaft immer noch nach unten" gehe (<http://www.rbc.ru/finances/13/10/2015 1561cefc09a79471ba16bb359>). Dazu passt auch die Aussage von Zentralbankchefin Elwira Nabiullina von voriger Woche, 2016 werde die russische Wirtschaft, entgegen bisheriger Regierungsprognosen, wohl erneut schrumpfen, wenn auch nur ein wenig.

Lange versuchte die russische Führung, die Krise vor allem mit äußeren Faktoren zu erklären: die "westliche« Finanzkrise, der fallende Ölpreis, die westlichen Sanktionen. Diese Versuche dauern zwar an, aber immer mehr Menschen im Land dämmert: Die Krise ist vor allem selbst gemacht. Alexander Ausan, Dekan der Wirtschaftswissenschaftlichen Fakultät der Moskauer Staatsuniversität, Mitglied zahlreicher Regierungskommissionen und qua Amt einer der wichtigsten russischen Ökonomen, flüchtet sich inzwischen in (wenn auch noch milden) Sarkasmus. Es gebe drei Möglichkeiten, die Krise zu überwinden, leitete er jüngst an seiner Fakultät die Vorstellung der russischen Ausgabe von Ralf Fücks' Buch »Intelligent Wachsen« zu einem ökologischen Wirtschaftsumbau ein, nämlich erstens, wenn der Ölpreis steigt, zweitens, wenn das Investitionsklima deutlich besser wird, oder drittens, wenn ein Wunder geschieht. Er, Ausan, halte die dritte Möglichkeit für die Wahrscheinlichste. Viele der zahlreich anwesenden Wirtschaftswissenschaftler lachten.

Was das "Wunder« wäre, sagte Ausan nicht, jedenfalls nicht ausdrücklich: eine politische Wende, die sich momentan in und für Russland aber (oh Wunder!) kaum jemand vorstellen kann. Jedenfalls nicht mit dieser Führung, die so fest im Sattel zu sitzen scheint, dass eben schon ein Wunder geschehen müsste, sollte sich das ändern. Wie es ohne dieses Wunder aussieht, will ich versuchen ein wenig am gerade von der Regierung vorgestellten Staatshaushalt für 2016 und einigen anderen Wirtschaftszahlen zu erläutern.

Erst einmal zur Einordnung. Der russische Staatshaushalt ist nach der massiven Rubelabwertung seit
Ende 2014 (in US-Dollar oder Euro gerechnet) ziemlich geschrumpft. Mit rund $220 \mathrm{Mrd}$. Euro entspricht er etwa dem von Belgien oder der Schweiz. Nicht wirklich riesig also für ein Land mit Weltmachtanspruch. Das US-Budget (weil sich das Land eben so gern mit den USA misst) ist rund $16 \mathrm{Mal}$ größer. Allein das Defizit des US-Haushalts ist zweimal größer als der gesamte russische Staatshaushalt. Im Verhältnis zum Bruttoinlandsprodukt (BIP) bleibt das russische Defizit mit geplanten 2,8\% für 2016 übrigens innerhalb der in der Eurozone geltenden Grenzen. Allerdings muss dafür auf der Einnahmenseite ein wenig getrickst werden. Die Regierung plant 2016 zwei Drittel des in den fetten 2000er Jahren angesparten Reservefonds auszugeben. Eine Kreditaufnahme zur Defizitdeckung wäre, trotz vergleichsweise geringer Staatsverschuldung, schwierig. Im Inland gibt es keine Banken, die so hohe Kredite vergeben könnten. Die Volkswirtschaften der BRICS-Länder erleben ebenfalls schwierige Zeiten. Im Westen gelten die (Finanz-) Sanktionen der USA, der EU und einer Reihe anderer Länder wegen des Kriegs in der Ostukraine.

Während die Regierung beim Haushalt für dieses Jahr noch auf einen steigenden Ölpreis gesetzt hatte (und sich im Jahresverlauf mehrfach korrigieren musste) gibt sie diese Hoffnung für 2016 auf. Der dem Haushalt zugrunde liegende Preis für ein Barrel ist mit 50 bis 55 US-Dollar bei einem Dollar-Rubel-Kurs von 1 zu 63 durchaus konservativ angesetzt. Der für die Haushaltsplanung wichtige Rubelpreis für Öl im Inland wird weiter mit 3100 bis 3300 Rubel pro Barrel angesetzt. Das entspricht einem langjährigen Mittel.

Trotz dieser auf den ersten Blick vorsichtigen Haltung auf der Einnahmenseite (wenn wir einmal von den zugeschossenen Reserven absehen, die es nächstes Jahr noch gibt, dann aber, sollte es nicht aufwärts gehen, nicht mehr) ist das Budget durchaus optimistisch. Denn die Regierung geht davon aus, dass die in diesem Jahr vor allem wegen der den Lebensmittelimport limitierenden russischen Gegensanktionen wahrscheinlich auf mehr als 15 Prozent steigende Inflation 2016 auf 5 bis 6 Prozent zurückgehen wird (was außer der Regierung aber kaum jemand glaubt). Außerdem liegt dem Haushalt die Annahme zugrunde, es werde ein, wenn auch sehr kleines, Wirtschaftswachstum von 0,7 Prozent geben (wovon, siehe oben, die Zentralbankchefin bereits in der gleichen Woche abgerückt ist, in der die Regierung den Haushaltsentwurf dem Parlament zugeleitet hat).

Wenig Hoffnung auf eine wirtschaftliche Erholung macht auch die Ausrichtung des Haushalts: mehr fürs 
Militär, immer weniger für Sozialleistungen. Zwar bleiben die Renten mit einem guten Viertel der Ausgaben der größte Posten, aber sie wachsen schon seit dem Vorjahr viel langsamer als die Inflation und das soll, den Regierungszahlen zufolge, auch 2016 so bleiben (selbst Regierungsökonomen fordern seit einiger Zeit offen die Anhebung des Renteneintrittsalters, weil anders das Rentensystem nicht zu retten sei). Der Militärhaushalt wächst dagegen weiter und soll 2016 bei umgerechnet gut $45 \mathrm{Mrd}$. Euro liegen.

Viel schlechter sieht es da aus, wo die Zukunft des Landes gemacht werden müsste. Die Finanzierung der Wohnungswirtschaft und des Wohnungsbaus wird um über 40 Prozent gekürzt, die Bildung um knapp 8 Prozent, die Gesundheitsversorgung um gut 10 Prozent (ein kleiner Vergleich: Pro Kopf liegen die Gesundheitsausgaben in Deutschland rund 50 Mal höher als in Russland). Es werden also, böse gesprochen, nicht nur mehr russische Soldaten sterben, sondern wohl auch Bürger, die mit Krieg gar nichts zu tun haben.

Um das Bild zu vervollständigen, noch einige weitere Wirtschaftszahlen: Die Industrieproduktion ist in den ersten neun Monaten des Jahres 2015 um 5 Prozent gesunken, in der verarbeitenden Industrie beträgt der Rückgang rund 10 Prozent. Selbst Landwirtschaft und Lebensmittelindustrie, die doch von den Gegensanktionen profitieren sollten, treten auf der Stelle. Das dürfte auch daran liegen, dass die Realeinkommen im Oktober schon im elften Monat hintereinander gesunken sind. Insgesamt erwartet die Regierung für 2015 einen Rückgang der Realeinkommen von 9 Prozent (Nichtregierungsökonomen kommen mitunter auf das Doppelte). Der einzige Lichtblick ist eine relative Stabilisierung seit Mai dieses Jahres (wobei "Lichtblick" wohl eine zu optimistische Wortwahl ist). Allerdings ist das eine Stabilität auf niedrigem Niveau. Positive Aussichten gibt es keine.

So weit, so schlecht also. Nun haben viele (darunter auch ich) den Erfolg und die Popularität Putins lange Zeit mit einem (ungeschriebenen) Gesellschaftsvertrag erklärt: Putin garantiert Stabilität und wachsenden Wohlstand für alle (wenn auch der Wohlstand für unterschiedliche Bevölkerungsgruppen unterschiedlich schnell stieg, so stieg er doch bis vor kurzem wirklich für alle), hat dafür aber politisch freie Hand. Dieser Logik folgend schlossen fast alle Zukunftsszenarien lange Zeit aus, dem Regime könne Gefahr durch direkt politische Themen wie Wahlen oder Menschenrechtsverletzungen drohen. Wenn (wenn!) es Unruhe geben werde, so dachten und schrieben wir, dann am ehesten aus wirtschaftlichen oder sozialen Gründen.

Nun sind wir im Jahr sieben der Wirtschaftskrise und der einzige, zugegebenermaßen (zu) kleine Auf- stand war der des Protestwinters 2011/2012 aufgrund der Wahlfälschungen und Putins Rückkehr ins Präsidentenamt. Nennenswerte soziale Proteste sind ausgeblieben und, so sehen es heute erneut die allermeisten Beobachter, werden auf absehbare Zeit ausbleiben. Das bedarf einer Erklärung.

Ein wichtiger Grund für die Ruhe dürfte in der (sowjetisch antrainierten) Anpassungsfähigkeit eines großen Teils der Bevölkerung an den wilden russischen Kapitalismus liegen und an der Anpassungsfähigkeit dieses Kapitalismus selbst. Wie schon in den 1990er Jahren sind hier Mechanismen wirksam, die zu einem weitgehenden, wenn auch stillschweigenden Einverständnis zwischen (arbeitender) Bevölkerung, Staat und Wirtschaft geführt haben. Trotz der hypertrophierten politischen Staatsgläubigkeit (vielleicht sogar gerade ihretwegen) erwarten die Menschen in Russland ohnehin kaum, dass der Staat ihnen beim alltäglichen Überleben hilft. Umso geringer ist dann in der Krise (und in gewisser Weise ist fast immer Krise, nur eben manchmal noch krisenhafter als üblich) die Enttäuschung, wenn man sich mal wieder selbst retten muss.

Diese Anpassungsleistung hat sich vor allem in vier Strängen vollzogen (ich stütze mich hier auf Angaben von Natalja Subarewitsch, Leiterin des Unabhängigen Instituts für Sozialpolitik). Der wichtigste ist die Reduzierung der Gehälter bei oft gleicher Arbeitsleistung. Das wurde bereits in den 1990er Jahren flächendeckend praktiziert. Für viele Menschen ist es wichtiger, ihre Arbeitsstelle nicht zu verlieren als Gehaltseinbußen hinzunehmen. Das liegt oft an der geringen Mobilität, außerhalb der Metropolen auch an meist fehlenden Alternativen, aber auch an sowjetischen Vorstellungen, ohne Job auch aus der Gesellschaft zu fallen. Bis zu 10 Prozent der Arbeitnehmer sind zudem inzwischen in eine Art unbezahlten Urlaub oder eine "Kurzarbeit» ohne Ausgleichzahlungen geschickt worden. Auch der Regierung passt diese Praxis, da die Arbeitslosenzahlen dadurch klein gehalten werden, weil die Menschen formal weiter als »beschäftigt« gelten.

Der zweite Grund ist die demographische Entwicklung. Aufgrund des Bevölkerungsverlusts verringert sich die Zahl der Menschen im Erwerbsalter jedes Jahr um 600.000 bis 800.000. Ins Erwerbsalter kommen seit einigen Jahren die äußerst geburtenschwachen Jahrgänge der 1990er, während die geburtenstarken Jahrgänge aus den 1950er und den 1960er Jahren in Rente gehen. Das entlastet den Arbeitsmarkt erheblich.

Der dritte Grund sind die Arbeitsmigranten. Offziell arbeiten in Russland zwei Millionen Ausländer. Nach inoffiziellen Schätzungen sind es aber zwischen vier und acht Millionen. Viele dieser Menschen kommen ohnehin nur zeitweise ins Land (vor allem aus ande- 
ren ehemaligen Sowjetrepubliken, also ohne ein Visum zu benötigen). Sie sind meist sehr flexibel und gehen zurück, wenn es keine Arbeit mehr gibt oder die Bezahlung zu gering ist.

Der vierte Grund ist ein weiteres Wachsen des ohnehin schon großen informellen Sektors der russischen Wirtschaft. Anfang der 2010er Jahre waren hier nach Schätzungen zwischen 17 und 18 Millionen Menschen beschäftigt, inzwischen sollen es zwischen 20 und 21 Millionen sein.

Diese Mechanismen sind die Basis der bisher weitgehenden Ruhe. Auf diese Basis aber hat der Kreml seit Jahren methodisch ein neues Narrativ gesetzt, nämlich die Behauptung, Russland sei eine belagerte und von Feinden umgebenen Festung. Die Annexion der Krim wird in großen Teilen der Bevölkerung zudem als Beweis dafür angesehen, dass Putin das Land "von den Knien" wieder aufgerichtet habe. Hinzu kommt die Legende vom einsamen Widerstand Russlands gegen die Weltherrschaft der USA. Es ist ein wenig wie bei Asterix. Alle Welt steht unter der Knute des Imperium Americanum, nur ein, nun ja, in diesem Fall nicht ganz kleines Land wehrt sich heldenhaft gegen diese Versklavung. Die (behaupteten!) Erfolge der russischen Rüstungsin- dustrie (ich erinnere an die große Militärparade auf dem Roten Platz zum Tag des Sieges am 9. Mai), das Atomraketenpotential und die neuerdings auch wieder »ruhmreiche" Armee spielen die Rolle des Zaubertranks. Mittels der Krimannexion, der angeblichen »Rettung« der russischsprachigen »Landsleute in der Ukraine vor den dortigen "Faschisten", aber auch, ganz neu, des »Antiterrorkampfs« gegen den IS in Syrien (den die Amerikaner, so tönt es immer wieder aus den russischen Fernsehern, nicht hinbekommen) wurde in gewisser Weise ein neuer "Gesellschaftsvertrag" geschlossen: Wenn es mit dem Wohlstand schon nicht klappt, dann wollen wir wenigstens wieder stolz sein können auf unser Land. Putin garantiert in den Augen vieler Menschen diesen Stolz.

Dieser Stolz, wieder wer zu sein in der Welt, geachtet, ja vielleicht sogar gefürchtet zu werden, überstrahlt bisher alle wirtschaftlichen Schwierigkeiten. Umfragen zufolge ist ein nicht unerheblicher Teil der Bevölkerung auch bereit, für ihn, den wiedergewonnenen Stolz, »den Gürtel enger zu schnallen«. Die große Frage wird sein, um wie viele Löcher?

Diesen und andere Texte finden Sie aufJens Siegerts Russlandblog < http://russland.boellblog.org/>.

\section{Wirtschaftskrise und soziale Lage in Umfragen}

\section{Grafik 5: Sind Sie einverstanden mit der Auffassung, dass sich Russland derzeit in einer Wirt- schaftskrise befindet?}

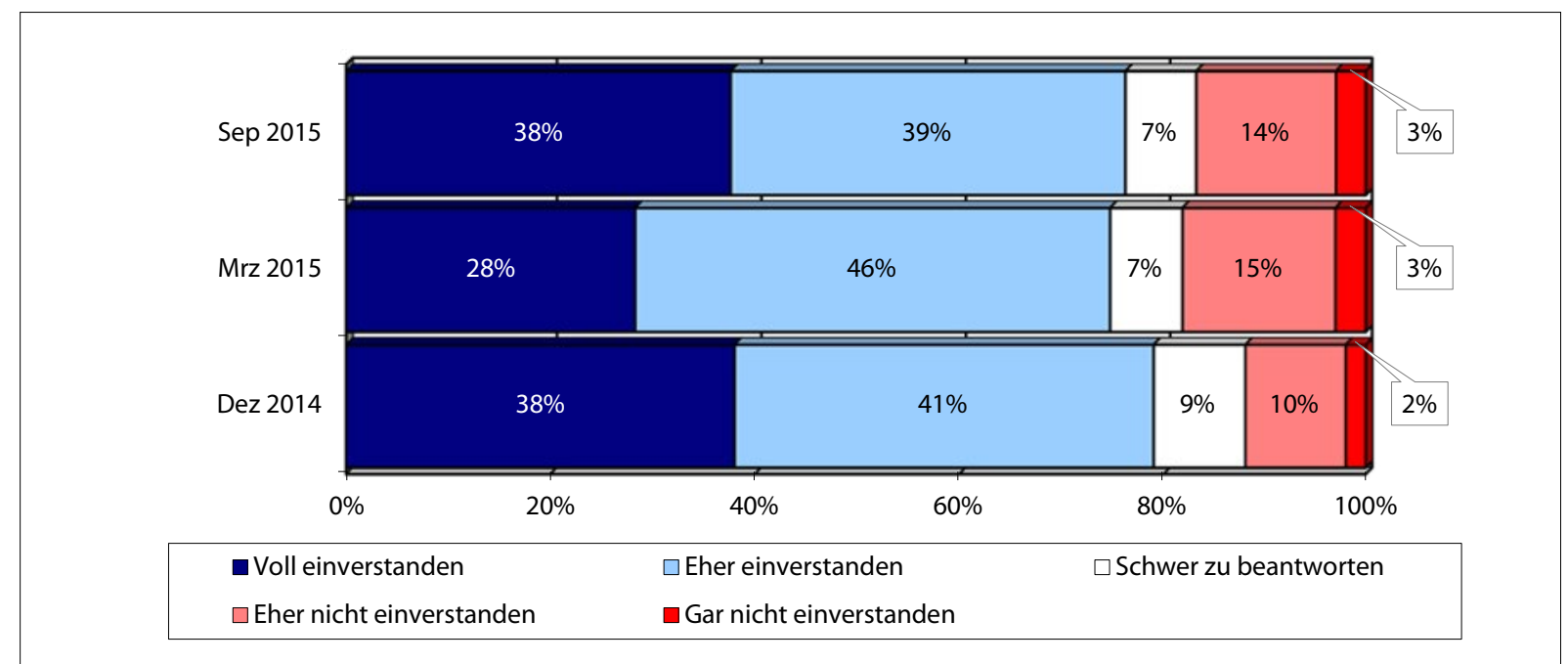

Quelle: Umfrage des Lewada-Zentrums im Zeitraum vom 18.-21. September 2015, N=1600<http://www.levada.ru/print/12-10-2015/ ekonomika-i-potreblenie>, 13. Oktober 2015 
Grafik 6: Hat sich Ihr tägliches Konsumverhalten oder das Ihrer Familie (bei Lebensmitteln, Produkten des täglichen Bedarfs, Medikamenten, Nutzung von Transportmitteln etc.) in den letzten 12 Monaten verändert, und wenn ja wie?

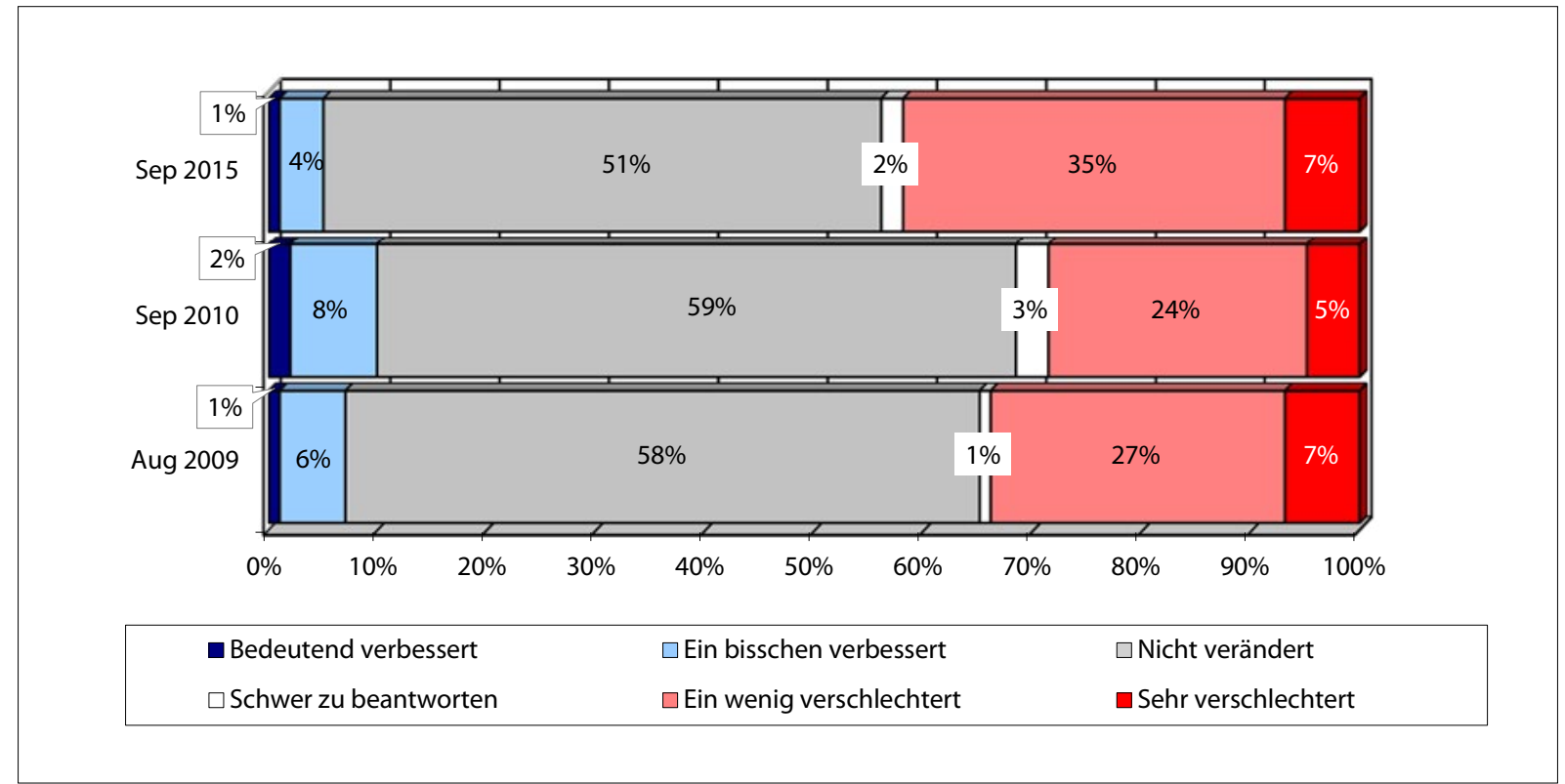

Quelle: Umfrage des Lewada-Zentrums im Zeitraum vom 18.-21. September 2015, N=1600 <http://www.levada.ru/print/12-10-2015/ ekonomika-i-potreblenie>, 13. Oktober 2015

Grafik 7: Worin liegt die Ursache dieser Krise (in \% derjenigen Befragten, die überzeugt sind, dass Russland sich in einer Wirtschaftskrise befindet; eine Antwortmöglichkeit, Sept. 2015)

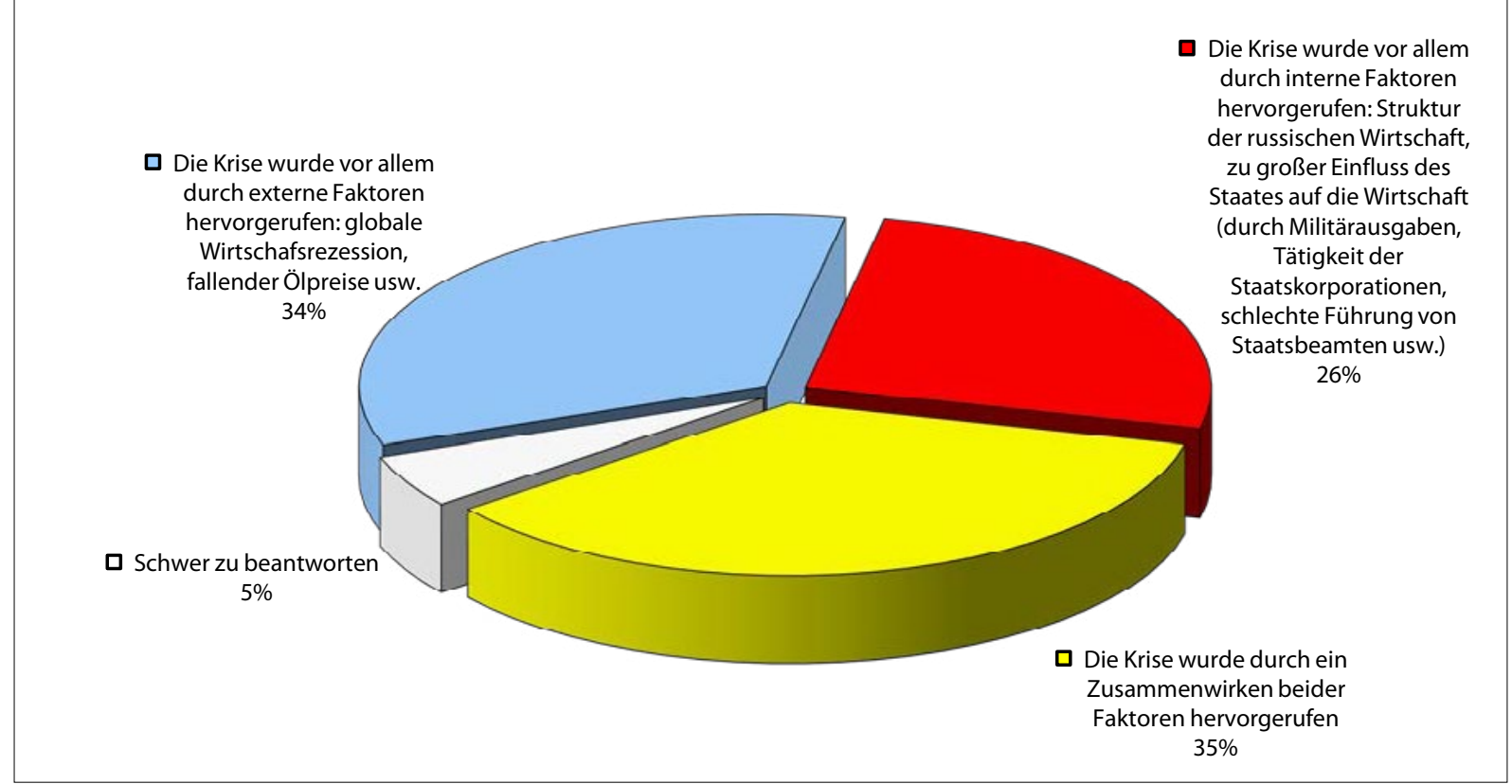

Quelle: Umfrage des Lewada-Zentrums im Zeitraum vom 18.-21. September 2015, $N=1600<$ http://www.levada.ru/print/12-10-2015/ ekonomika-i-potreblenie>, 13. Oktober 2015 
Grafik 8: Wie verhalten Sie sich zu dem Vorschlag, dass zum Zwecke einer Lösung des Rentenproblems die Praxis der Frühverrentung (gegen Abfindung) für verschiedene Kategorien von Arbeitnehmern abgeschafft werden soll?

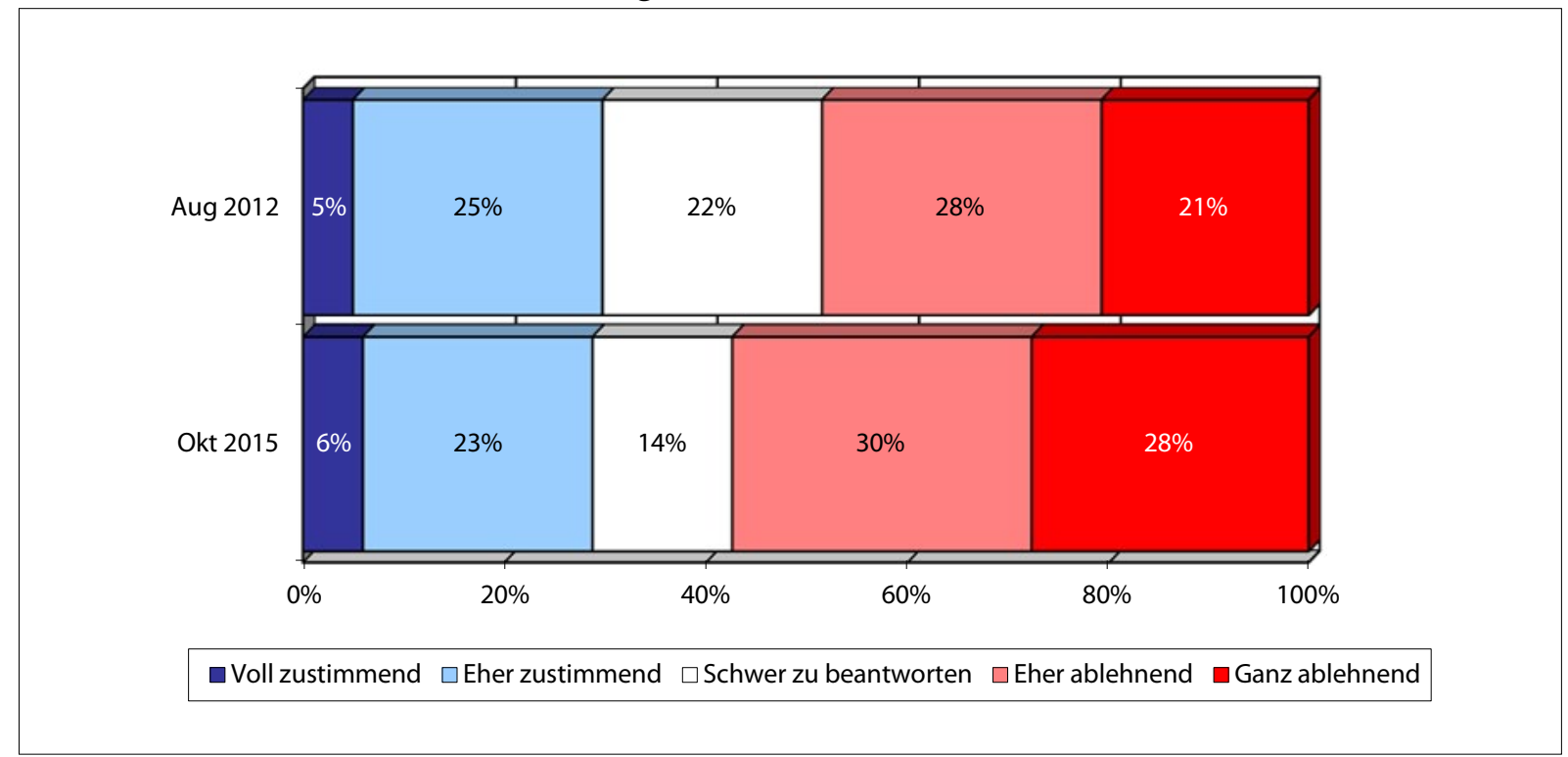

Quelle: Umfrage des Lewada-Zentrums im Zeitraum vom 2.-5. Oktober 2015, N=1600 <http://www.levada.ru/print/15-10-2015/ pensionnaya-sistema>, 15. Oktober 2015

Grafik 9: Wie verhalten Sie sich zu dem Vorschlag, dass zum Zwecke einer Lösung des Rentenproblems allmählich das Rentenalter angehoben werden soll?

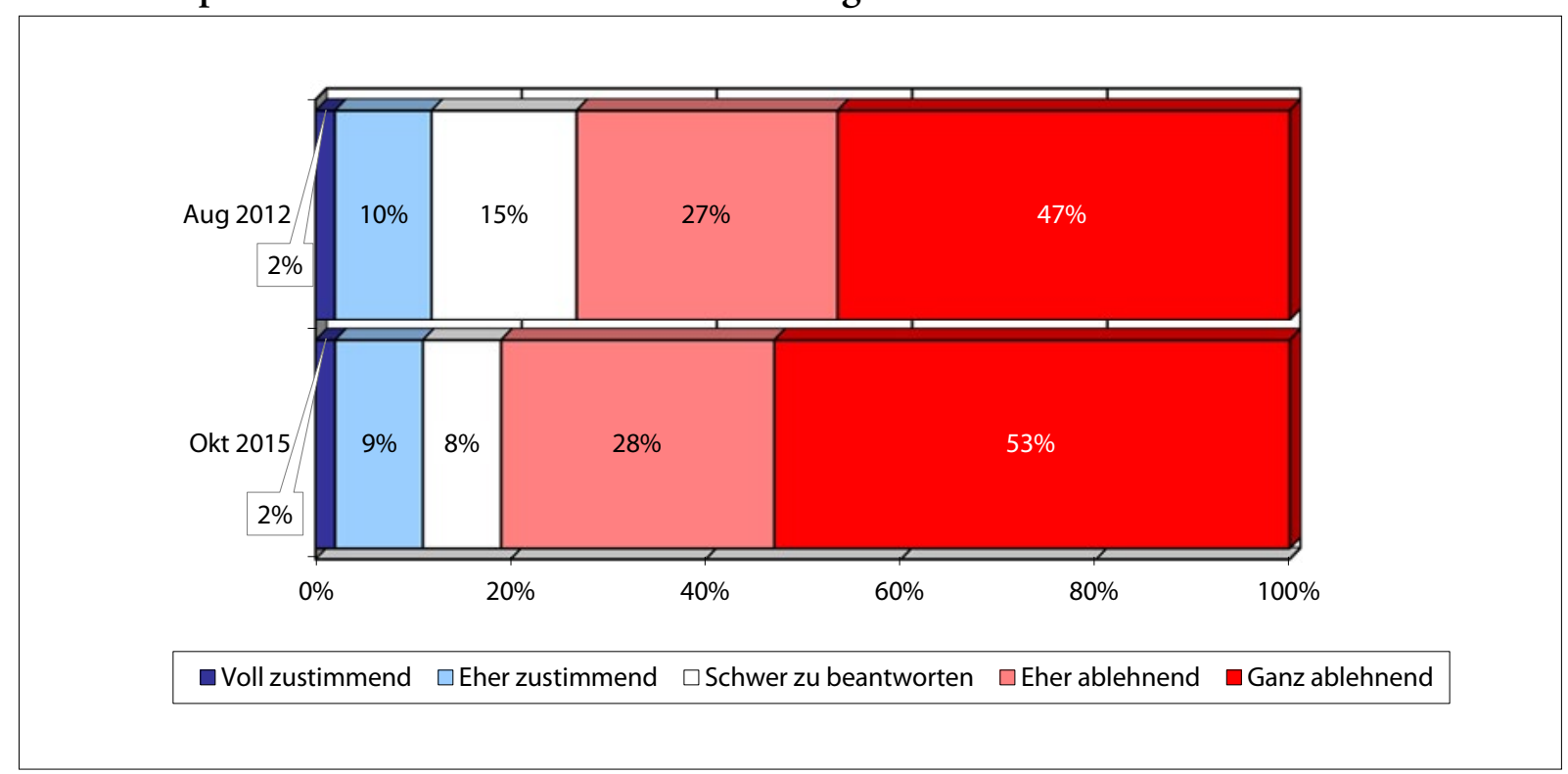

Quelle: Umfrage des Lewada-Zentrums im Zeitraum vom 2.-5. Oktober 2015, N=1600 <http://www.levada.ru/print/15-10-2015/ pensionnaya-sistema>, 15. Oktober 2015 
Grafik 10: Was denken Sie, ist die Zahl der armen Menschen in unserem Land in den letzten fünf Jahren gestiegen oder gesunken? (geschlossene Frage, eine Antwortmöglichkeit)

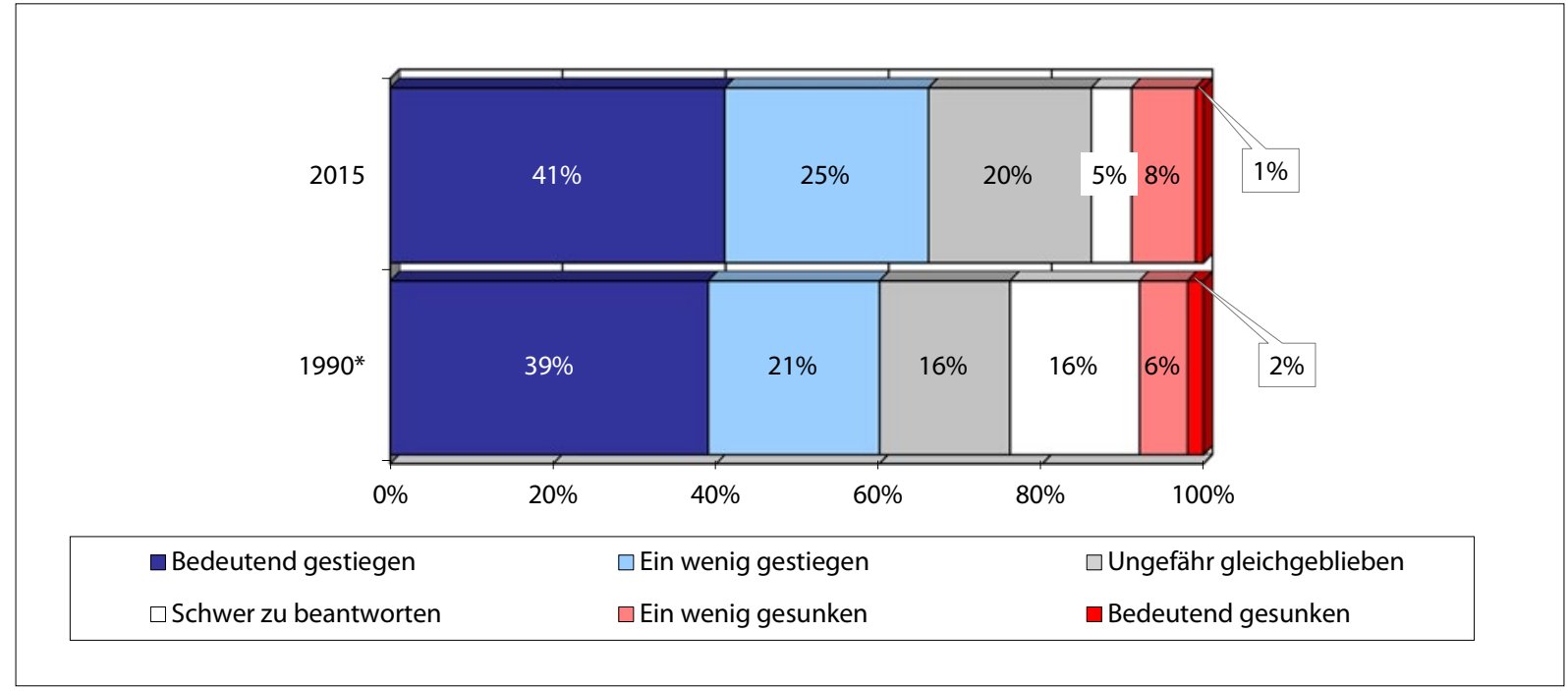

* 1990 wurden nur 1280 Personen befragt

Quelle: Umfrage des Meinungsforschungsinstituts WZIOM im Zeitraum vom 11.-12. Juli 2015, N=1600 <http://wciom.ru/index. php?id=236\&uid=115416>, 2. Oktober 2015

Grafik 11: Erinnern Sie sich an eine Zeit in Ihrem Leben, als Sie sich selbst arm fühlten? Wenn ja, wann war das? (geschlossene Frage, unbegrenzte Antwortmöglichkeiten)

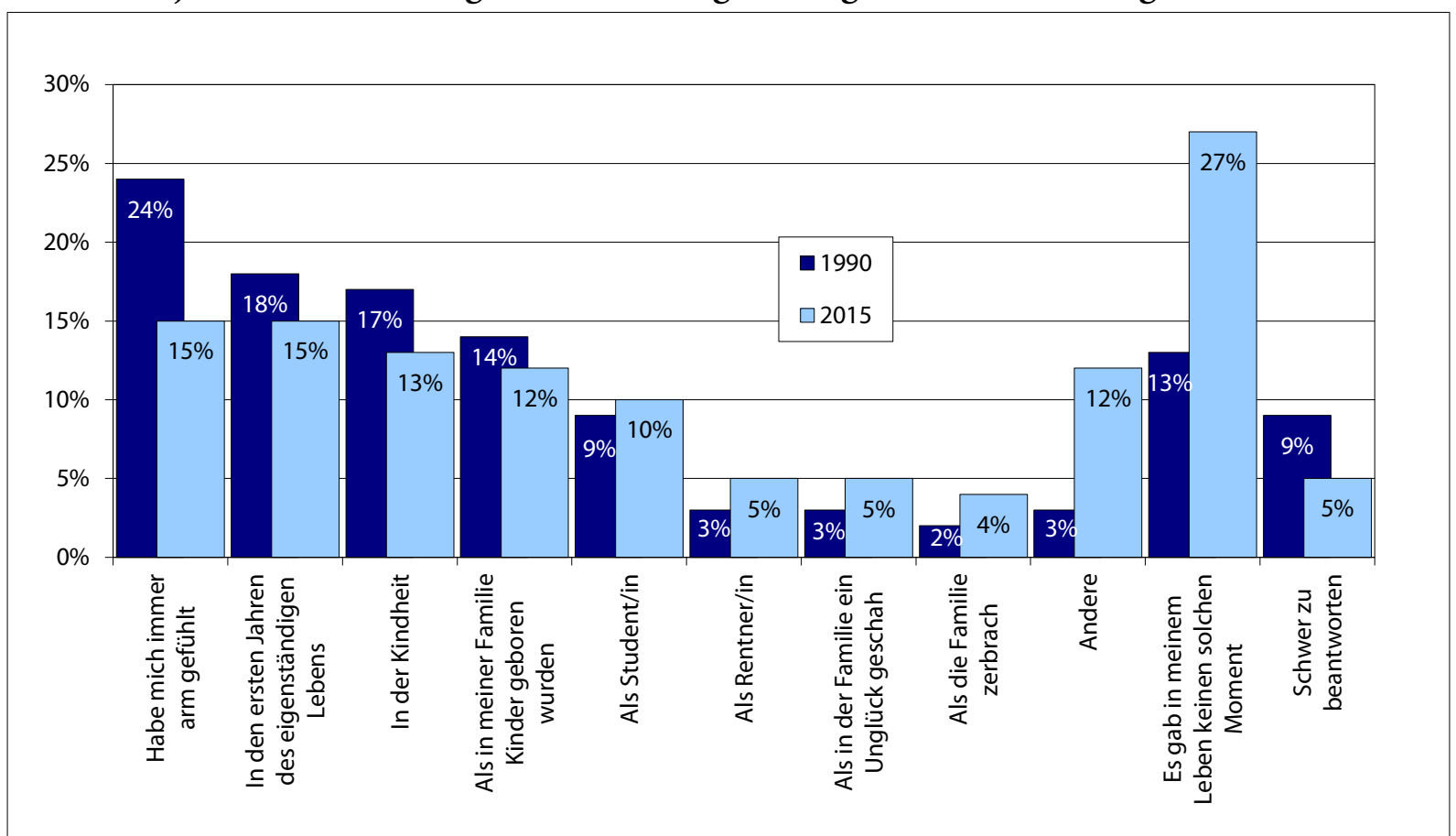

Quelle: Umfrage des Meinungsforschungsinstituts WZIOM im Zeitraum vom 11.-12. Juli 2015, N=1600 <http://wciom.ru/index. php?id=236\&uid=115416>, 2. Oktober 2015 


\section{Russen zum Einsatz von Streitkräften in Syrien}

Grafik 12: Unterstützen Sie die Entscheidung des Föderationsrates der Entsendung russischer Streitkräfte ins Ausland zuzustimmen?

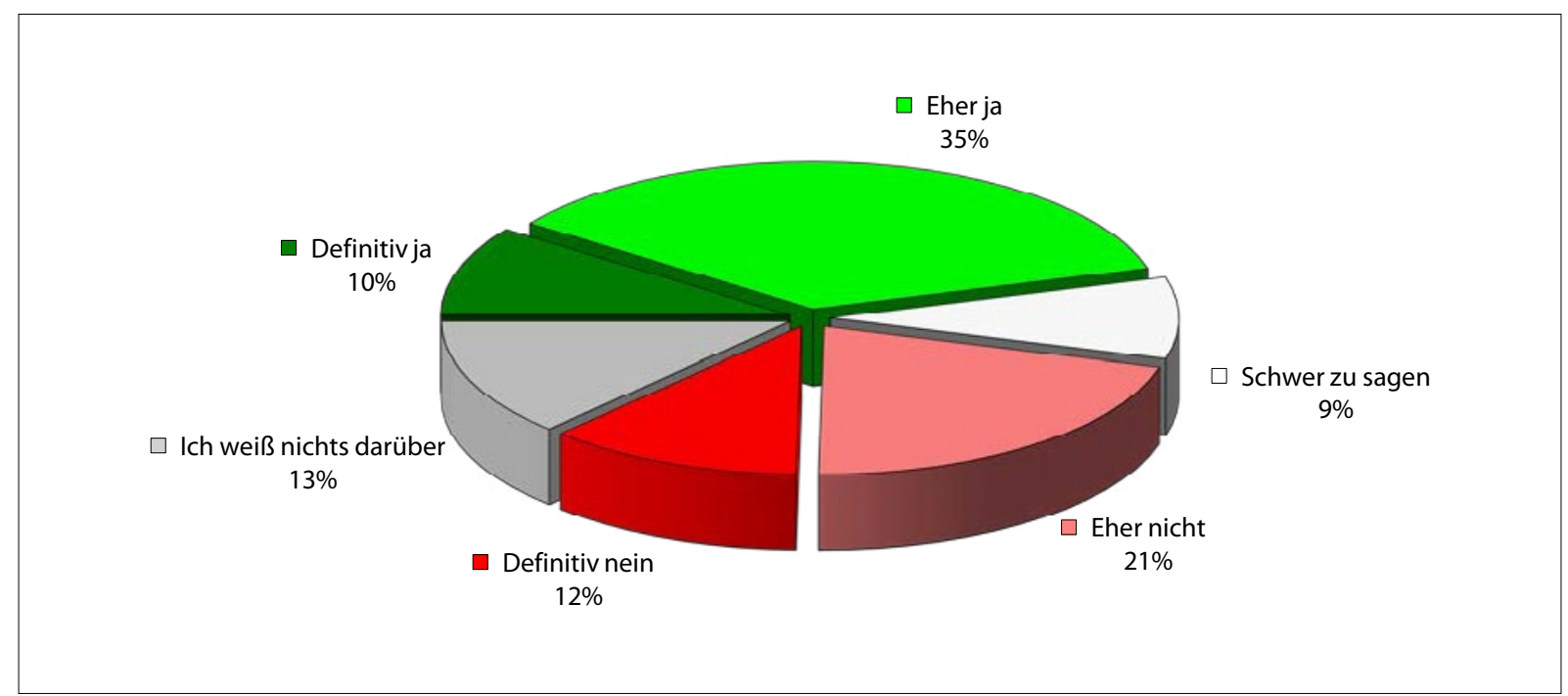

Quelle: Repräsentative Meinungsumfrage des Lewada-Zentrums, 2.-5. Oktober 2015, $N=1600$ <http://www.levada.ru/08-10-2015/ udary-po-islamskomu-gosudarstvu-podderzhali-72-grazhdan>,veröffentlicht am 8. Oktober 2015

Grafik 13: Vor kurzem wurde berichtet, dass die russischen Luftstreitkräfte mit der Bombardierung von Zielen in Syrien begonnen haben. Welchen Aussagen stimmen Sie am ehesten zu?

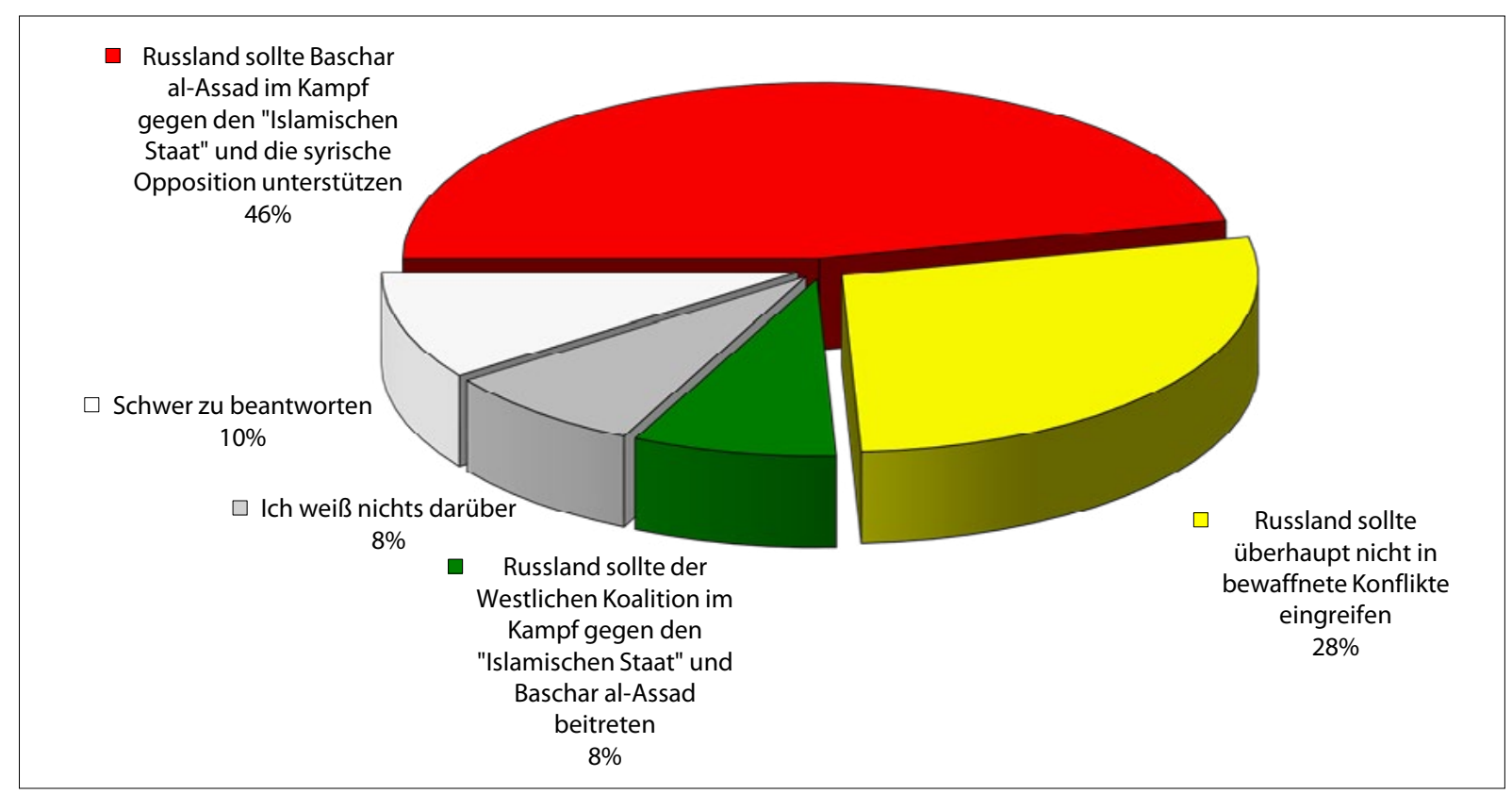

Quelle: Repräsentative Meinungsumfrage des Lewada-Zentrums, 2.-5. Oktober 2015, $N=1600$ <http://www.levada.ru/08-10-2015/ udary-po-islamskomu-gosudarstvu-podderzhali-72-grazhdan>,veröffentlicht am 8. Oktober 2015 
Grafik 14: Was denken Sie, ist es möglich, dass Russlands bewaffnete Intervention in den SyrienKonflikt sich in ein »neues« Afghanistan für Russland entwickelt?

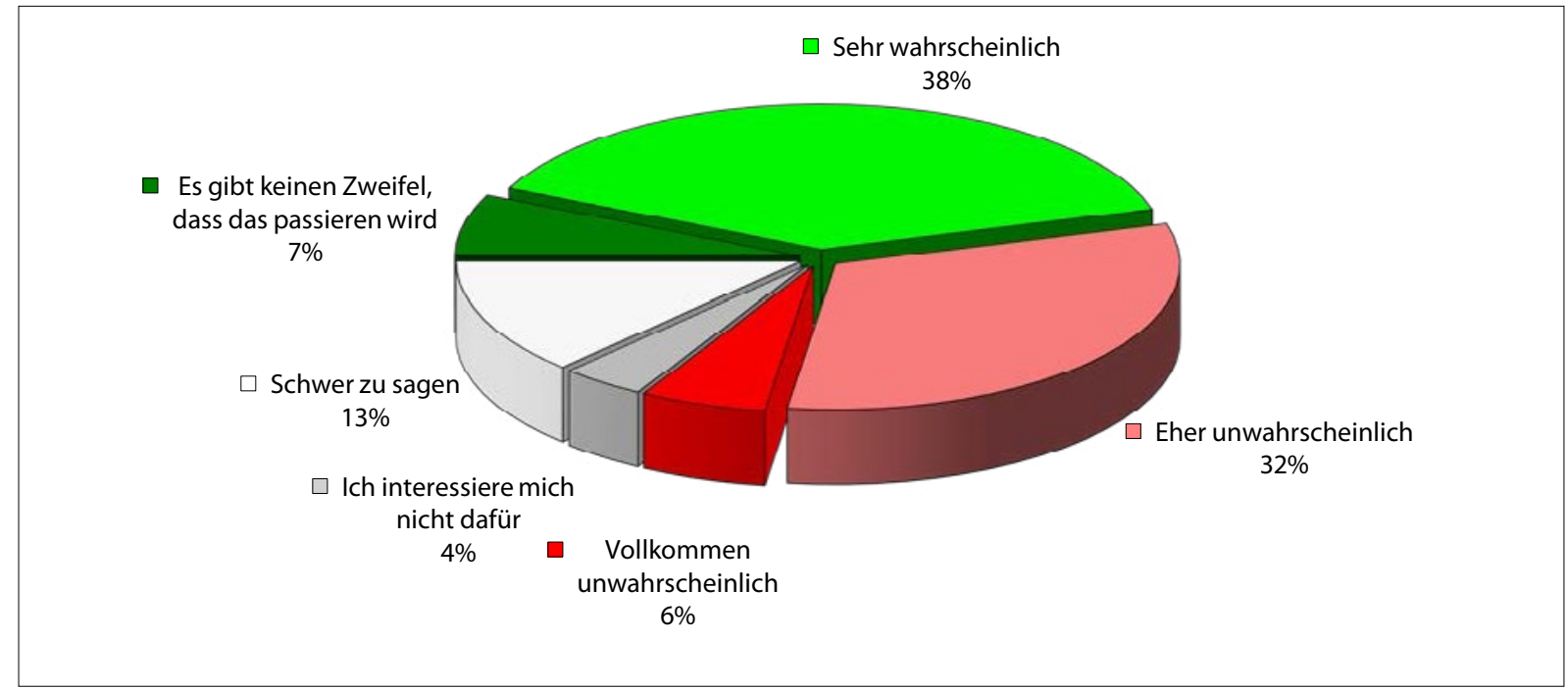

Quelle: Repräsentative Meinungsumfrage des Lewada-Zentrums, 2.-5. Oktober 2015, N=1600 <http://www.levada.ru/08-10-2015/ udary-po-islamskomu-gosudarstvu-podderzhali-72-grazhdan>,veröffentlicht am 8. Oktober 2015

\section{AUS RUSSISCHEN BLOGS}

\section{Swetlana Alexijewitsch - eine russische Schriftstellerin?}

Der Nobelpreis für Literatur ist 2015 an die sowjetische und belorussische Schriftstellerin Swetlana Alexijewitsch verliehen worden. Die russischsprachige Autorin wurde von der Königlich Schwedischen Akademie der Wissenschaften "für ihr vielstimmiges Werk, das dem Leiden und Mut in unserer Zeit ein Denkmal setzt« geehrt. Sie war zuvor bereits 2005 mit dem Buchpreis der US-amerikanischen Literaturkritiker, 2011 mit dem polnischen Ryszard-KapuścinskiPreis für literarische Reportagen und 2013 mit dem Friedenspreis des Deutschen Buchhandels ausgezeichnet worden. Alexijewitsch ist eine der meist gelesenen russischsprachigen Autoren in der Welt und gilt als Klassiker russischer zeitgenössischer Literatur.

Swetlana Alexijewitsch wurde 1948 im westukrainischen Stanislaw (heute Iwano-Frankiwsk) geboren und zog als kleines Kind in die Belarussische Sowjetrepublik um. Sie studierte Journalismus in Minsk, arbeitete nach dem Studium als Korrespondentin lokaler Zeitungen und sammelte Erinnerungen von Kriegszeugen in Belarus - in derjenigen Sowjetrepublik, die am meisten unter der deutschen Besatzung gelitten hatte. Bereits in ihrem ersten Buch »Der Krieg hat kein weibliches Gesicht", das nach langen Auseinandersetzungen mit der sowjetischen Zensur erst 1985 erschien, entwickelt Alexijewitsch ihr eigenes literarisches Genre. Sie befasst sich mit der Alltagsgeschichte sowjetischer Soldatinnen im Zweiten Weltkrieg und schildert anhand von Memoiren, Interviews und Reportagen die dunkelsten Kapitel des Lebens in der Sowjetunion. Ihre engagierte Dokumentarprosa lässt diejenigen Menschen zu Wort kommen, die sonst niemanden interessierten, beispielsweise Frauen und Mütter der im sowjetischen Afghanistan-Krieg gefallenen Soldaten in dem Buch "Zinkjungen" oder Zeugen der Atomkatastrophe in ihrem Werk "Tschernobyl. Eine Chronik der Zukunft«. In ihrem letzten Buch »Secondhand-Zeit« veröffentlicht Alexijewitsch »Stimmen einer Utopie«, zusammengesetzt aus Monologen ihrer Zeitgenossen über den Zerfall der Sowjetunion und den Umbruch der 1990er Jahre in unterschiedlichen postsowjetischen Ländern.

Seit Anfang der 2000er Jahre lebt Alexijewitsch in Italien, Frankreich und Deutschland. Sie kritisierte stets autoritäre Regime im postsowjetischen Raum, vor allem Aleksandr Lukaschenka, dem sie einen brutalen Umgang mit der 
Opposition in ihrem Heimatland vorwarf. Nach der Krim-Annexion wurde auch der russische Machthaber Putin wegen der Aufstachelung der »russischen Welt» zu einer Offensive gegen die prowestliche Kiewer Regierung immer wieder von der Schriftstellerin harsch kritisiert. Vor wenigen Tagen sprach sie in einem Interview über ihre eigene Identität: sie sei ein Teil der »belorussischen Welt«, möge aber sehr die »gute, humanistische russische Welt«. Nur mit der "Welt von Berija, Stalin, Putin und Schoigu« verbinde sie nichts, so Alexijewitsch.

Die Nachricht über die Verleihung des Nobelpreises für Literatur 2015 an Alexijewitsch spaltete erneut die Öffentlichkeit in Russland. Die Blogger fragen sich, ob Alexijewitsch als eine russische Schriftstellerin gelten könne, und worin diese berüchtigte russische Welt überhaupt bestehe. Wegen der »antirussischen Haltung« der Nobelpreisträgerin wurde die Preisvergabe in den national-patriotischen Kreisen Russlands überwiegend mit Skepsis aufgenommen. Protagonisten des neuen russischen Nationalismus, der Schriftsteller Sachar Prilepin und der Publizist Jegor Cholmogorow, werfen der Nobelpreisträgerin Russophobie vor und kritisieren das Nobelkomitee für eine politische Entscheidung, die eine Art Antwort auf die Außenpolitik Putins darstelle. Die demokratisch orientierten Journalisten und Blogger reagierten mit Verwunderung auf die Kritik der russischen Patrioten bezüglich der Preisvergabe an eine russischsprachige Autorin. Der Fernsehjournalist Nikolaj Swanidse und der Philosoph Kirill Martynow sehen gerade in der Antikriegsliteratur Alexijewitschs die wahre »russische Welt«. Der Blogger Dmitrij Bawyrin empört sich über die Äußerungen der Patrioten, Alexijewitsch sei russophob, und sagt, fast alle Klassiker russischer Literatur, von Pushkin bis Tolstoi, könnten wegen ihrer Kritik an der russischen Gesellschaft auch als russophob gelten. Der Theaterregisseur Pawel Rudnew betont, dass in der »russischen Welt« nicht die Wahrheit über die eigene Geschichte als Wert zähle, sondern allein Loyalität (gegenüber den Regierenden).

\section{Martynow: " Nein zum Krieg`, das ist in diesem Jahr die Nobel-Botschaft an die Welt."}

"Alexijewitsch, das ist eine sehr alte und wichtige Geschichte. Das war eine Autorin, die über das ganz Harte, Schwarze geschrieben hat, worüber man unbedingt hätte schreiben sollen, von dem sich die russische Gesellschaft aber stets verschämt abwendete, während man versuchte, über die Runden zu kommen und Geld zu verdienen: über den beschämenden Krieg, über den Verrat aus an den eigenen Leuten, über Angst und Schmerz, und auch über den Versuch der Heroisierung von Dingen in der Vergangenheit, die eigentlich Anlass zur Trauer sind.

Ich habe mich oft an Alexijewitsch erinnert, als ich davon sprach, dass Russland über den Krieg in Afghanistan geschwiegen hat, und dass das eine große Schande ist. Die Amerikaner haben Tausende Bücher über Vietnam, wir haben nur ungelenke Erinnerungen der "Afghanen« [ehem. sowjetische Soldaten mit Kriegserfahrung in Afghanistan; d. Red.] und das Schweigen. Aber eben auch Alexijewitsch!

Sie war Symbol der russischen ignorance: Sie hat zwar über das Wichtigste geschrieben, war aber nur eine Schriftstellerin der zweiten Reihe, Verfasserin von unbequemer, schwer lesbarer »Dokumentar-Prosa«, etwas ab vom Schuss als ob das Volk, die Russen, immerfort andere, interessantere Themen oder Dramen gehabt hätten.

Und jetzt hat sie den Preis bekommen, merkwürdig: Vor meinen Augen widerfährt das zum ersten Mal einem Menschen, der diesen Preis durch sein Leben verdient hat.

'Nein zum Krieg`, das ist in diesem Jahr die Nobel-Botschaft an die Welt." Kirill Martynov am 08.10.2015 auf Facebook <https://www.facebook.com/kmartynov/posts/1082163501817417>

\section{Prilepin: Der Literaturnobelpreis an Alexijewitsch ist Antwort des Westens auf die souveräne Politik Russlands}

"[...] Im Grunde hätten sie auch Wasil Bykow den Preis verleihen können. Der hat seinerzeit das sowjetische Regime gehasst und hatte viele Fragen an Russland, war aber ein großer Schriftsteller. Und Belarusse. Aber es geht ja nicht um Literatur. [...]

All die russischen Westler, Liberalen und [fortschrittsgläubigen] Progressisten, die jetzt frohlocken, sollten sich wohl besser bewusst machen, dass sie zusammen mit dem übrigen Russlands verachtet werden, aber wozu sollten die sich das bewusst machen? [...]

Vor fünf, sechs Jahren habe ich in Paris gesagt, und davor auf der Buchmesse in London (Lew Danilkin und Basinskij waren dabei, sie können das bezeugen), dass der Nobelpreis sich an die russische Literatur erinnert, sobald russische U-Boote vor Europa herumschwimmen. `Gebt [den Preis] mal ohne die U-Boote habe ich damals gescherzt. [...]

Sie müssen verstehen: Dieser Preis entspringt dem Gefühl einer enormen Erniedrigung. Erst die Olympischen Spiele, danach die Krim, dann wurden die DNR ["Volksrepublik Donezk"] und die LNR [»Volksrepublik Luhansk"] praktisch aus dem Territorium der Ukraine ausgegliedert. Jetzt Syrien, die Bomben, die vom Kaspischen Meer aus fliegen, wohin sie wollen. Besser gesagt: dorthin, wohin es befohlen wird. Irgendeine Antwort musste man ja geben. 
Dabei verfiel man dann auf die ungeschickteste, ärmlichste Variante: nämlich den Preis an eine gute Journalistin zu vergeben, die vor allem durch ihre - selbst für ihre Gleichgesinnten - erstaunlich banalen Interviews mit dem Refrain bekannt ist: 'Russland hat alle getötet, getötet, getötet, hat immer getötet und wird töten; haltet dieses Übel auf; diese Sklaven werden nie aufhören, Sklaven zu sein; da gibt's Stalin und Popen, und Sie wissen ja, wie das endet; und besonders ich weiß es genauk. [...]

Eigentlich ist das ein Preis an Russland. An seine Unabhängigkeit, seinen Einfluss, seine Rolle in der Welt. Wir können diese Unabhängigkeit und diese Rolle abgeben. Macht nichts. Aber - was für eine Ansage!.

Dreißig Jahre lang hatte man ja kaum ernsthaft vorgehabt, den Preis [an Alexijewitsch] zu verleihen. Und nun: Ein Jahr Arbeit, und schon konnte der Schuss losgehen. Gelobt sei Swetlana Alexijewitsch, Genossen!

Am Tag der Preisverleihung war ich ausnehmend guter Laune, obwohl ich auch sonst kaum meckere. Ich habe sogar Champagner getrunken. Wir haben das geschafft. Übrigens, wollen Sie eine Prognose? Im nächsten Jahr wird der Preis an irgendeine Person aus der dritten oder fünften Reihe vergeben. Man hat ja so gut begonnen, da muss man doch im Rhythmus bleiben... und da wird es dann schon nicht mehr um Russland gehen. Zu Russland soviel: Es wird [den Preis] auch bekommen. Und nicht nur ein Mal. Man muss nur im selben Geiste weitermachen. Wo sind übrigens unsere U-Boote?»

Sachar Prilepin am 09.10.2015 auf izvestia.ru <http://izvestia.ru/news/592832>

\section{Swanidze: Antwort an Prilepin}

„Ein russischer Schriftsteller kann nicht Militarismus predigen und lehren, kann den Krieg nicht lieben, vermissen, jaulend danach verlangen und das dann Patriotismus nennen.

Swetlana Alexijewitsch liebt Menschen, hat Mitleid mit ihnen. Gerade deswegen hat sie den Nobelpreis bekommen, und nicht Sie [Prilepin], und nicht Limonow, und nicht Prochanow.

Und ich bitte Sie, nicht jeden Krieg - von Afghanistan bis Syrien - als Vaterländischen zu verkaufen. Vor allem nicht als Großen Vaterländischen."

Nikolaj Swanidse am 12.10.2015 auf Echo Moskwy <http://echo.msk.ru/blog/svanidze_n/1639024-echo/>

\section{Cholmogorow: »Über die russophobe Alexijewitsch und das philologische Spital«}

"Den Jubel unserer Demokratie-Schizos kann man nachvollziehen. Sie sind der absoluten Überzeugung, dass die bleichgesichtigen Brüder ihnen einen gewaltigen Rammbock gegen das »Regime« zurechtgelegt haben. Das Problem ist nur, dass die Reputationsmaschine kaputt gegangen ist. Zum einen, aus objektiven Gründen: Schließlich kann man ja nicht ewig Preise an politisch korrekte drittklassige Leute vergeben, wenn neben ihnen beispielsweise Tom Stoppard, das non plus ultra der gegenwärtigen Eliten-Literatur, oder George Martin, sein Pendant für die Massenliteratur, auf der Liste stehen.

Wissen Sie noch, wer im letzten Jahr den »Nobel«[-Preis] für Literatur bekommen hat? Und wer im vorletzten? Der »Weltliteraturpreis" von Nobel ist zu einem philologischen Hospiz geworden und interessiert insofern niemanden mehr. Der zweite Grund ist der, dass die »Helden der liberalen Händeschüttler« in Russland, außerhalb ihres eigenen engen Kreises, immer weniger von Interesse sind.

Dank westlicher Stiftungen und Preise bastelt sich die russische Opposition eine Parallelwelt, in der Swjaginzew, Nemzow und Alexijewitsch die Köpfe beherrschen. Und sie hoffen, durch Kundgebungen und Abrams [US-amerikanische Kampfpanzer vom Typ M1; d. Red.] irgendwann diese parallele Welt dem ganzen Volk aufzudrängen, wie eine zweite, falsche Erinnerung.

Doch soweit wird es nicht kommen. Die Niederlage des »arabischen Frühlings« hat gezeigt, dass es nicht einmal gelingt, selbst Gesellschaften mit weniger entwickeltem Kulturpotenzial dieses »Kaugummi« aufzunötigen. Russland haben sie jedoch schon unwiederbringlich verloren. Ihm [Russland] sind sie schlichtweg gleichgültig. [...]

Selbst wenn unser Volk enttäuscht werden sollte, wird es deshalb Nawalnyj, Poroschenko und Alexijewitsch nicht stärker zugeneigt sein. [...]«

Jegor Cholmogorow am 09.10.2015 auf Livejournal.com <http://holmogor.livejournal.com/6876169.html>

\section{Bawyrin: Wenn Alexijewitsch russophob ist, dann sind fast alle russische Klassiker auch russophob}

"Hallo, seid ihr noch ganz dicht? Wenn Alexijewitsch russophob ist, dann ist fast das ganze "goldene Zeitalter« der russischen Literatur russophob. Habt ihr den jungen Puschkin vergessen? Und das "ungewaschene Russland « Lermontows? Die Stadt Glupow [der Dummköpfe] von Saltykow-Schtschedrin? Habt ihr die Tagebücher von Turgenjew 
gelesen? Und »Hadschi Murat« von Tolstoi? Ganz zu schweigen von Pasternak und Dowlatow. Was bleibt denn dann "echt Russisches«, wenn die Vorliebe für Anzüge und Uniformen zur Grundbedingung wird? Dostojewskij, Tjuttschew, Leskow (bei letzterem sind Zweifel angebracht, da er wie ein Rohrspatz auf die ROK [Russische Orthodoxe Kirche] schimpfte). Ein großer Schriftsteller ist in der Regel Regime-Kritiker. Nicht nur in Russland, sondern auch in den USA, wo viele große Schriftsteller bezeichnenderweise nach links tendierten und das offizielle Washington nicht mochten." Dmitri Bywarin am 09.10.2015 auf Facebook <https://www.facebook.com/bavyrin/posts/971430386249902>

\section{Rudnew: Der einzige und unerschütterliche Wert scheint Loyalität zu sein}

"Die Reaktion der professionellen Patrioten auf die Preisverleihung an Alexijewitsch bestätigt nur, was ohnehin offensichtlich ist. Alexijewitsch ist Autorin von zwei Büchern über die Tragödie des Großen Vaterländischen Krieges, dessen Gedenken die Verfechter eines starken Staates tränenreich den Eid geschworen haben. Sie hat Hunderte lebende Zeitzeuginnen befragt; die Schriftstellerin hat sie zum Sprechen gebracht. Nun stellt sich aber heraus, dass die russische Sprache mit ihrer Bedeutung für die Welt nicht von Wert ist.

Die Wahrheit des einzelnen Menschen kein Wert ist.

Die Geschichte des Landes jenseits ideologischer Mythen wertlos ist.

Die Erinnerung an den Krieg keinerlei Wert darstellt.

Als einziger und unerschütterlicher Wert bleibt Loyalität. Loyalität, und weiter nichts."

Pawel Rudnew am 10.10.2015 auf Facebook <https://www.facebook.com/pavel.rudnev.9/posts/10204992647717680>

Ausgewählt und zusammengefasst von Sergey Medvedev, Berlin

(Die Blogs, auf die verwiesen wird, sind in russischer Sprache verfasst)

\section{Grafik 15: Nennen Sie bitte ihren Lieblingsautor (eine Antwort; angeführt werden die 19 am häufigsten genannten Autoren)}

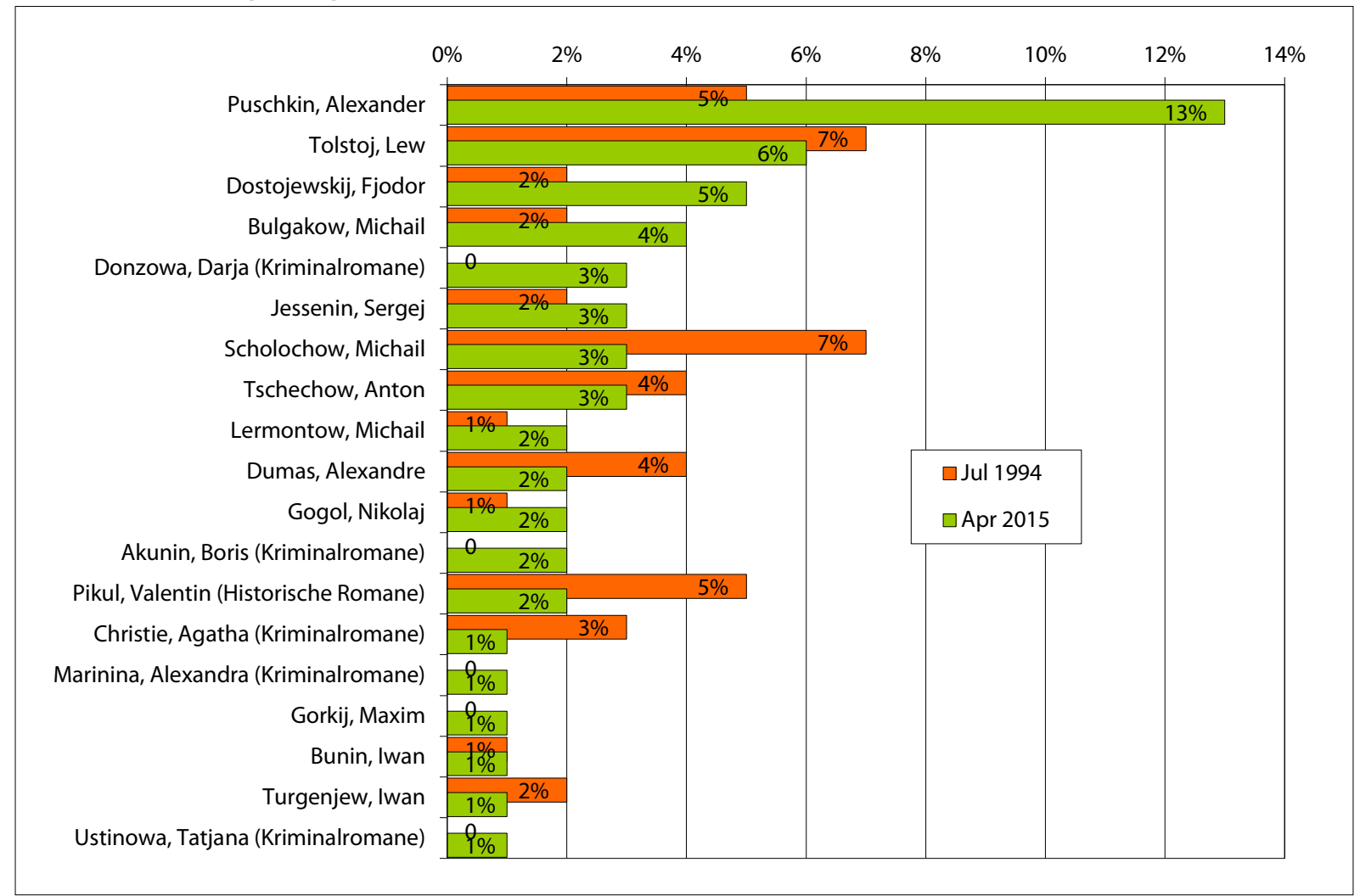

Quelle: Repräsentative Meinungsumfrage des Lewada-Zentrums, 17.-20. April2015, N=1600 <http://www.levada.ru/print/19-05-2015/ rossiyane-o-chtenii>, veröffentlicht am 21. Mai 2015 


\section{8. - 22. Oktober 2015}

\begin{tabular}{|c|c|}
\hline 08.10 .2015 & $\begin{array}{l}\text { In Grosnyj werden drei mutmaßliche IS-Kämpfer im Rahmen einer Anti-Terror-Operation getötet. Das rus- } \\
\text { sische Innenministerium gibt an, die Kämpfer seien in Syrien ausgebildet worden und hätten eine Serie von } \\
\text { Anschlägen geplant. }\end{array}$ \\
\hline 08.- 11.10.2015 & $\begin{array}{l}\text { Mit dem Großen Preis von Sotschi findet zum zweiten Mal ein Formel 1-Rennen auf einer russischen Renn- } \\
\text { strecke statt. Präsident Wladimir Putin sowie eine Reihe internationaler Prominente aus dem Sport-Business } \\
\text { sind unter den Zuschauern. Auch saudische Regierungsvertreter sind angereist. Im Anschluss an das Rennen } \\
\text { finden Konsultationen zwischen Regierungsvertretern Russlands und Saudi-Arabiens statt. }\end{array}$ \\
\hline 09.10 .2015 & $\begin{array}{l}\text { Auf finnische Initiative hin führen Präsident Wladimir Putin und sein Amtskollege Sauli Niinistö ein Tele- } \\
\text { fongespräch. Thema ist der aktuelle Stand der Wirtschafts- und Handelsbeziehungen zwischen beiden Län- } \\
\text { dern. Putin informiert Niinistö über die Ergebnisse der Pariser Gespräche im Normandie-Format sowie über } \\
\text { die russische Militäroperation in Syrien. }\end{array}$ \\
\hline 09.10 .2015 & $\begin{array}{l}\text { Nach Angaben des russischen Wirtschaftsministers Alexej Uljakajew ist Russland gezwungen, das föderale } \\
\text { Zielprogramm zur wirtschaftlichen Entwicklung der Krim anzupassen. Grund seien Probleme der russischen } \\
\text { Wirtschaft, weshalb eine Reihe von Maßnahmen erst im nächsten Jahr finanziert werden könnten. }\end{array}$ \\
\hline 09.10 .2015 & $\begin{array}{l}\text { Der Leiter der Oppositionsbewegung »Linke Front«, Sergej Udalzow, der sich seit vergangenem Jahr in Lager- } \\
\text { haft befindet, kündigt einen Hungerstreik an. Anlass ist ein nach Angaben von Udalzows Frau Anastasija unbe- } \\
\text { gründeter Verweis durch die Verwaltung der Strafvollzugskolonie in Tambowsk und die daraufhin erfolgte } \\
\text { Verlegung Udalzows in eine Strafarrestzelle. Udalzow vermute, dass damit eine vorzeitige Entlassung, die in } \\
\text { Kürze beantragt werden kann, verhindert werden soll. }\end{array}$ \\
\hline 10.10 .2015 & $\begin{array}{l}\text { Sitzung des nationalen Sicherheitsrats in Sotschi. Themen sind die Lage in Syrien sowie Operationen der Welt- } \\
\text { raumstreitkräfte zur Unterstützung der Aktivitäten in Syrien. }\end{array}$ \\
\hline 11.10 .2015 & $\begin{array}{l}\text { In einer Resolution der Parlamentarischen Versammlung der NATO werden strengere Wirtschaftssanktio- } \\
\text { nen gegenüber Russland gefordert für den Fall, dass Russland den Waffenstillstand in der Ostukraine nicht } \\
\text { einhält. Die Parlamentarier fordern außerdem, dass bestehende Sanktionen beibehalten werden solange das } \\
\text { Minsker Abkommen nicht gänzlich umgesetzt sei. }\end{array}$ \\
\hline 11.10 .2015 & $\begin{array}{l}\text { Der russische Botschafter in Großbritannien, Aleksandr Jakowenko wendet sich an das britische Außenmi- } \\
\text { nisterium mit der Forderung nach Klärung britischer Medienberichte, denen zufolge es britischen Kampf- } \\
\text { fliegern, die an Operationen gegen die Terrormiliz »IS « im Irak teilnehmen, erlaubt sei, russische Kampfflug- } \\
\text { zeuge abzuschießen. Außerdem betont Jakowenko, dass Russland noch keine Antwort auf seine Anfrage nach } \\
\text { Informationen zur Dislozierung von IS-Kämpfern in Syrien erhalten habe. }\end{array}$ \\
\hline 12.10 .2015 & $\begin{array}{l}\text { In Moskau werden wegen Terrorverdacht } 10 \text { Personen, vorwiegend zentralasiatischer Herkunft, festgenom- } \\
\text { men. Bei den Verdächtigen sei sprengstoffartiges Material gefunden worden. Nach Angaben des Nationalen } \\
\text { Anti-Terrorkomitees habe die Gruppe einen Anschlag in Moskau geplant. }\end{array}$ \\
\hline 12.10 .2015 & $\begin{array}{l}\text { Medien melden, dass dem Entwurf des föderalen Haushaltsplans für } 2016 \text { zufolge die Regierung für das kom- } \\
\text { mende Jahr eine Kürzung der Gehälter von Ärzten, Lehrern und Sozialarbeitern plane. }\end{array}$ \\
\hline 12.10 .2015 & $\begin{array}{l}\text { Das russische Justizministerium streicht zehn Organisationen aus dem NGO-Register »ausländischer Agen- } \\
\text { ten«. Davon würden vier Organisationen nicht mehr als »ausländischer Agent« agieren; sechs Organisatio- } \\
\text { nen hätten sich aufgelöst. }\end{array}$ \\
\hline 12.10 .2015 & $\begin{array}{l}\text { In Inguschetien werden im Rahmen einer Antiterror-Operation drei Kämpfer getötet und vier festgenommen. } \\
\text { Die Spezialeinheiten des FSB kündigen an, die Operation in der Gegend der Siedlung Gazi-Jurt fortzusetzen. }\end{array}$ \\
\hline 13.10 .2015 & $\begin{array}{l}\text { Der niederländische Untersuchungsrat für Sicherheit (»Dutch Safety Board«) veröffentlicht den offiziellen } \\
\text { Abschlussbericht über die Ursachen des Absturzes der malaysischen Boeing des Fluges MH-17 im Juli } 2014 . \\
\text { Der Bericht }<\text { http://www.onderzoeksraad.nl/>) bestätigt den Verdacht eines Abschusses durch eine Boden- } \\
\text { Luft-Rakete des russischen Typs "Buk« }(9 \mathrm{~N} 314 \mathrm{M}) \text { aus der Ostukraine. Der Bericht enthält auch Angaben } \\
\text { zu dem möglichen Abschussgebiet, aus dem die Rakete gestartet worden sei und das sich unter Kontrolle der } \\
\text { Separatisten befunden habe. Gleichzeitig kritisiert der Rat die ukrainischen Behörden, weil diese den Luft- } \\
\text { raum nicht für Verkehrsmaschinen gesperrt haben. Am gleichen Tag veröffentlicht auch das russische Rüs- } \\
\text { tungsunternehmen Almas-Antej einen eigenen Bericht, der besagt, dass der Raketentyp russischen Ursprungs } \\
\text { veraltet und nicht mehr im Bestand der russischen, jedoch der ukrainischen Streitkräfte, sei <http://tass.ru/ } \\
\text { boeing-presentation/vvedenie>. Außerdem behauptet Almas-Antej, durch ein Experiment nachgewiesen zu } \\
\text { haben, dass die Raketen nicht aus dem von Separatisten kontrollierten Snishne (Sneshnoje) abgeschossen } \\
\text { worden sein könne. }\end{array}$ \\
\hline
\end{tabular}




\begin{tabular}{|c|c|}
\hline 13.10 .2015 & $\begin{array}{l}\text { Präsident Wladimir Putin kündigt an, dass Russland in Syrien auf eine politische Lösung des Konfliktes } \\
\text { abziele. Er bedaure, dass die Zusammenarbeit mit den USA nur auf der Ebene der Militärs stattfände. Zum } \\
\text { Zwecke einer Konsolidierung der politischen Bemühungen wolle er eine Delegation unter der Führung von } \\
\text { Ministerpräsident Dmitrij Medwedew nach Washington schicken. }\end{array}$ \\
\hline 13.10 .2015 & $\begin{array}{l}\text { Präsident Wladimir Putin leitet eine Kabinettsitzung. Themen sind die vorläufigen Ergebnisse bei der »Umset- } \\
\text { zung der Ansprache des Präsidenten« an die Föderationsversammlung im Dezember 2014. Desweiteren wird } \\
\text { die Situation der insolventen Fluggesellschaft »Transaereo« diskutiert. }\end{array}$ \\
\hline 13.10 .2015 & $\begin{array}{l}\text { Sechs Berufssoldaten einer Militäreinheit in der Stadt Majkop (Republik Adygeja) werden wegen eigenmäch- } \\
\text { tigen Verlassens der Einheit (eines Stützpunkts im Gebiet Rostow unweit von einem Lager der Separatisten) } \\
\text { von einem Garnisonsgericht in Majkop zu Haftstrafen von } 6 \text { Monaten bis zu } 2 \text { Jahren verurteilt. Die Beru- } \\
\text { fungsverhandlung eines Soldaten soll am 22. Oktober vor dem Gericht des Militärbezirks Nordkaukasus in } \\
\text { Rostow stattfinden. }\end{array}$ \\
\hline 14.10 .2015 & $\begin{array}{l}\text { Präsident Wladimir Putin macht sich persönlich ein Bild von den Fortschritten beim Bau des Weltraumbahn- } \\
\text { hofs »Wostotschnyj«. Nach etlichen Verzögerungen und Problemen beim Bau hatte Putin persönlich die Kon- } \\
\text { trolle über das Bauprojekt übernommen. Der erste Raketenstart ist für Ende des Jahres geplant. }\end{array}$ \\
\hline 14.10 .2015 & $\begin{array}{l}\text { Nach Angaben des kaukasischen Nachrichtenportals »Kawkasskij Usel« hat die Zahl der Opfer der militäri- } \\
\text { schen Auseinandersetzungen in Tschetschenien im Oktober im Vergleich zu den Vorjahren ein Rekordhoch } \\
\text { erreicht. Bei Spezialoperationen in der Hauptstadt Grosnyj seien allein im Oktober sechs Personen getötet } \\
\text { und zahlreiche Kämpfer und Sicherheitsbeamte verletzt worden. }\end{array}$ \\
\hline 14.10 .2015 & $\begin{array}{l}\text { Der Russische Föderale Zolldienst (FTS) erklärt, dass russische Verbraucher nach wie vor sanktionierte Pro- } \\
\text { dukte über das Internet beziehen können. Gleichzeitig wird betont, dass der FTS den Verkauf von Waren, } \\
\text { die unter die Sanktionen fallen, nicht erlaubt. }\end{array}$ \\
\hline 14.10 .2015 & $\begin{array}{l}\text { Nach Angaben von Außenminister Sergej Lawrow haben die USA dem russischen Angebot, eine Delegation } \\
\text { zu Beratungen über das Vorgehen in Syrien nach Washington zu schicken, eine Absage erteilt. }\end{array}$ \\
\hline 14.10 .2015 & $\begin{array}{l}\text { Russische und amerikanische Militärexperten führen zum dritten Mal eine Videokonferenz über ein Abkom- } \\
\text { men durch, das die Sicherheit im syrischen Luftraum sicherstellen soll. Die Stimmung wird von beiden Sei- } \\
\text { ten als konstruktiv und professionell bezeichnet. }\end{array}$ \\
\hline 15.10 .2015 & $\begin{array}{l}\text { Das russische Katastrophenschutzministerium schickt den } 41 \text {. Hilfskonvoi in die Region Donbass. Die etwa } \\
100 \text { LKWs haben ca. } 1100 \text { Tonnen humanitäre Güter geladen }\end{array}$ \\
\hline 15.10 .2015 & $\begin{array}{l}\text { Die russische Strafermittlungsbehörde teilt mit, dass ein Terroranschlag auf eine Moschee in der Stadt Pyt- } \\
\text { Jach im Autonomen Bezirk der Chanten und Mansen vereitelt wurde. Die mutmaßlichen Attentäter seien } \\
\text { Teil der Terrormiliz IS und hätten sich auf der Flucht vor einer Strafverfolgung in der Türkei in Russland } \\
\text { versteckt gehalten. }\end{array}$ \\
\hline 15.10 .2015 & $\begin{array}{l}\text { Nach Angaben des ukrainischen Ministerpräsidenten Arsenij Jazenjuk plant die Ukraine, Russland vor inter- } \\
\text { nationalen Gerichtshöfen zu verklagen. Mehrere Klagen seien bereits vorbereitet, unter anderem eine Klage } \\
\text { auf finanzielle Entschädigung in Höhe von } 1 \text { Milliarde Euro für den Schaden, der durch die russische Anne- } \\
\text { xion der Krim und die Interventionen in Donezk und Luhansk entstanden sei. }\end{array}$ \\
\hline 15.10 .2015 & $\begin{array}{l}\text { Die russische Regierung beschließt ein Gesetzesvorhaben, das den kapitalbildenden Teil der Renten } 2016 \\
\text { einfriert und die Anpassung der Renten für das kommende Jahr auf } 4 \% \text { beschränkt, entgegen der bisheri- } \\
\text { gen Praxis, die die Anpassung an die Inflationsrate bindet (2015-11,9\%). Das Rentenalter soll vorerst nicht } \\
\text { angehoben werden. }\end{array}$ \\
\hline 16.10 .2015 & $\begin{array}{l}\text { Präsident Wladimir Putin hält sich zu einem Staatsbesuch in der kasachischen Hauptstadt Astana auf. Er } \\
\text { führt dort Gespräche mit dem kasachischen Staatspräsidenten Nursultan Nasarbajew. Dabei geht es insbe- } \\
\text { sondere um die Aktivitäten der Eurasischen Wirtschaftsunion. }\end{array}$ \\
\hline 16.10 .2015 & $\begin{array}{l}\text { Russland und Pakistan unterzeichnen ein bilaterales Abkommen über den Bau der Gaspipeline »Nord-Süd«. } \\
\text { Die Pipeline soll auf einer Länge von } 1100 \mathrm{~km} \text { von Karatschi nach Lahore führen. Sie soll bis Ende } 2019 \text { fer- } \\
\text { tiggestellt und vom russischen Unternehmen »RT - Globale Ressourcen«, das der Staatskorporation »Rostech» } \\
\text { angehört, gebaut werden. }\end{array}$ \\
\hline
\end{tabular}




\begin{tabular}{|c|c|}
\hline 16.10 .2015 & $\begin{array}{l}\text { Im kasachischen Nationalpark Borowoje findet ein Treffen des Rates der Staats- und Regierungschefs der GUS } \\
\text { statt. Thema ist die weitere Zusammenarbeit der GUS-Mitgliedstaaten im humanitären, sicherheitspolitischen } \\
\text { sowie militärischen Bereich. Anschließend findet ein Treffen des Hohen Rates der Eurasischen Wirtschafts- } \\
\text { union statt, an dem die Präsidenten Wladimir Putin, Aljaksandr Lukaschenka (Belarus), Nursultan Nasar- } \\
\text { bajew (Kasachstan), Sersh Sargsjan (Armenien) sowie Almasbek Atambajew (Kirgistan) teilnehmen. Dabei } \\
\text { geht es um die Perspektiven des Integrationsprozesses. }\end{array}$ \\
\hline 16.10 .2015 & $\begin{array}{l}\text { Nach dem bereits die britische Fluggesellschaft EasyJet und das deutsche Unternehmen Air Berlin angekün- } \\
\text { digt haben, ihre Flüge nach Moskau einstellen zu wollen, erklärt nun auch die estnische Gesellschaft »Esto- } \\
\text { nian Air«, dass Flüge von Tallinn nach Moskau gestrichen werden sollen. }\end{array}$ \\
\hline 17.10 .2015 & $\begin{array}{l}\text { In Moskau findet auf dem Suworow-Platz eine Demonstration mit ca. } 150 \text { Teilnehmern gegen die russische } \\
\text { Militärintervention in Syrien statt. Aufgerufen zum Protest haben die Bewegungen »Solidarnost« sowie »Par- } \\
\text { tei des 5. Dezember«. Das Thema der Demo lautet: »Syrien - das zweite Afghanistan?». }\end{array}$ \\
\hline 17.10 .2015 & $\begin{array}{l}\text { Ein Flugzeug des russischen Katastrophenschutzministeriums fliegt } 56 \text { russische Staatsbürger sowie Staats- } \\
\text { bürger weiterer GUS-Staaten aus Syrien aus. Zuvor hatte das Flugzeug } 20 \text { Tonnen Hilfsgüter nach Latakia } \\
\text { gebracht. Bulgarien verwehrte Russland erneut die Überfluggenehmigung. }\end{array}$ \\
\hline 18.10 .2015 & $\begin{array}{l}\text { Vertreter des russischen Präsidenten, darunter der Sonderbeauftragte für den Nahen Osten und Afrika Michail } \\
\text { Bogdanow, treffen in Kairo mit Repräsentanten der syrischen Opposition zusammen, zu denen auch der frü- } \\
\text { here Vorsitzenden der Nationalen Koalition der syrischen Revolutions- und Oppositionskräfte Ahmed al- } \\
\text { Dscharba gehört. Die Gespräche behandeln die Frage einer politischen Regelung der Syrien-Krise auf der } \\
\text { Grundlage des Genfer Kommuniqué vom 30. Juni 2012. }\end{array}$ \\
\hline 18.10 .2015 & $\begin{array}{l}\text { In einer Reihe von europäischen und asiatischen Hauptstädten, unter anderem in Berlin und Moskau, fin- } \\
\text { den vor russischen Botschaften Demonstrationen der syrischen Diaspora zur Unterstützung des russischen } \\
\text { Vorgehens in Syrien statt. }\end{array}$ \\
\hline 19.10 .2015 & $\begin{array}{l}\text { Im Kaspischen Meer findet in der Nähe von Astrachan eine russisch-iranische Marineübung statt, die } 14 \text { Tage } \\
\text { dauern soll. Geübt wird die Zusammenarbeit zwischen den beiden Seestreitkräften. Ferner soll die gemein- } \\
\text { same Ausbildung von Matrosen gefördert werden. }\end{array}$ \\
\hline 19.10 .2015 & $\begin{array}{l}\text { Das Kreisgericht Rjasan im Gebiet Rjasan gibt dem Antrag des inhaftierten Bolotnaja-Aktivisten Aleksej Poli- } \\
\text { chovitsch auf vorzeitige Haftentlassung auf Bewährung statt. }\end{array}$ \\
\hline 19.10 .2015 & $\begin{array}{l}\text { Der Präsident der international nicht anerkannten Republik Südossetien, Leonid Tibilow, kündigt an, dass } \\
\text { ein Referendum über die Eingliederung der Republik in die Russische Föderation geplant sei. Dies müsse } \\
\text { jedoch erst mit der russischen Seiten abgestimmt werden. }\end{array}$ \\
\hline 19.10 .2015 & $\begin{array}{l}\text { Die in Großbritannien ansässige syrische Beobachtungsstelle für Menschenrechte teilt mit, dass durch rus- } \\
\text { sische Raketenangriffe eine Beerdigungsprozession in der Nähe der syrischen Stadt Homs getroffen und vier } \\
\text { Menschen getötet worden seien. }\end{array}$ \\
\hline 20.10 .2015 & $\begin{array}{l}\text { Nach Angaben des Wissenschaftsmagazins »Nature« müssen Wissenschaftler des Instituts für physisch-che- } \\
\text { mische Biologie der Moskauer Staatlichen Universität die Ergebnisse ihrer Arbeit vor der Publikation dem } \\
\text { Inlandsgeheimdienst FSB vorlegen. }\end{array}$ \\
\hline 20.10 .2015 & $\begin{array}{l}\text { Nach Angaben der Nachrichtenagentur Reuters und der syrischen Beobachtungsstelle für Menschenrechte } \\
\text { haben die russischen Luftangriffe in Syrien bislang etwa } 370 \text { Menschen das Leben gekostet; ein Drittel von } \\
\text { ihnen seien Zivilisten, darunter } 36 \text { Kinder. Die übrigen seien Kämpfer sowohl des Islamischen Staates als } \\
\text { auch anderer Oppositionsgruppen gewesen. }\end{array}$ \\
\hline 20.10 .2015 & $\begin{array}{l}\text { Präsident Wladimir Putin gibt bekannt, dass Mitarbeiter des Inlandsgeheimdienstes FSB } 2015 \text { insgesamt } 20 \text { ter- } \\
\text { roristische Anschläge vereitelt hätten. Des weiteren seien im Rahmen von Anti-Terror-Operationen } 112 \text { Kämp- } \\
\text { fer getötet worden, davon } 26 \text { Anführer. } 560 \text { Mitglieder von bewaffneten Gruppen seien festgenommen worden. }\end{array}$ \\
\hline 20.10 .2015 & $\begin{array}{l}\text { Die Meldung der Nachrichtenagentur Reuters, dass nach Informationen der syrischen Regierung drei rus- } \\
\text { sische Soldaten in der syrischen Provinz Latakia getötet worden seien, wird von der russischen Botschaft in } \\
\text { Syrien dementiert. }\end{array}$ \\
\hline 20.10 .2015 & $\begin{array}{l}\text { Der syrische Präsident Baschar al-Assad reist zu einem Arbeitsbesuch nach Moskau. Assad und Putin erör- } \\
\text { tern das gemeinsame Vorgehen im Kampf gegen den »Islamischen Staat« in Syrien. }\end{array}$ \\
\hline 21.10 .2015 & $\begin{array}{l}\text { Die russische Fluggesellschaft S7 wird durch den Kauf eines Aktienpakets Hauptanteilseigner des bankrot- } \\
\text { ten Flugunternehmens "Transaero«. Im September noch hatte Aeroflot angekündigt Transaero zu überneh- } \\
\text { men, war dann aber vom Kauf zurückgetreten. }\end{array}$ \\
\hline
\end{tabular}




\begin{tabular}{|l|l|}
\hline 21.10.2015 & $\begin{array}{l}\text { Präsident Vladimir Putin informiert den türkischen Staatspräsidenten Erdogan, den König von Saudi-Ara- } \\
\text { bien, Salman ibn Abd al-Aziz, den Präsidenten von Ägypten und den König von Jordanien über die Ergeb- } \\
\text { nisse seiner Gespräche mit dem syrischen Präsidenten Baschar al-Assad. }\end{array}$ \\
\hline 22.10.2015 & $\begin{array}{l}\text { Justizminister Alexander Konowalow erklärt, dass eine Reihe von Entscheidungen des Straßburger Gerichts- } \\
\text { hofes für Menschenrechte in Russland nicht übernommen würden, da sie juristische Widersprüche enthielten. }\end{array}$ \\
\hline
\end{tabular}

Sie können die gesamte Chronik seit 1964 auch auf <http://www.laender-analysen.de/russland/> unter dem Link »Chronik« lesen.

Die Russland-Analysen werden von Mangold Consulting GmbH unterstützt.

\section{MANGOLD}

$\mathrm{C} \circ \mathrm{n} \mathrm{s} u$ । $\mathrm{t}$ i $\mathrm{n} \mathrm{g}$

Herausgeber: Forschungsstelle Osteuropa an der Universität Bremen und Deutsche Gesellschaft für Osteuropakunde

Die Meinungen, die in den Russland-Analysen geäußert werden, geben ausschließlich die Auffassung der Autoren wieder.

Abdruck und sonstige publizistische Nutzung sind nach Rücksprache mit der Redaktion gestattet.

Redaktion: Hans-Henning Schröder (verantwortlich), Nadja Douglas

Sprachredaktion: Hartmut Schröder

Satz: Matthias Neumann

Russland-Analysen-Layout: Cengiz Kibaroglu, Matthias Neumann und Michael Clemens

Alle Ausgaben der Russland-Analysen sind mit Themen- und Autorenindex archiviert unter www.laender-analysen.de

Die Russland-Analysen werden im Rahmen eines Lizenzvertrages in das Internetangebot der Bundeszentrale für politische Bildung (www.bpb.de) aufgenommen.

Die Russland-Analysen werden im Rahmen der Datenbank World Affairs Online (WAO) ausgewertet und sind im Portal IREON www.ireon-portal.de recherchierbar. ISSN 1613-3390 @ 2015 by Forschungsstelle Osteuropa, Bremen

Forschungsstelle 0steuropa • Publikationsreferat • Klagenfurter Str. 3 • 28359 Bremen • Telefon: + 49 421-218-69600 • Telefax: + 49 421-218-69607

e-mail: publikationsreferat@osteuropa.uni-bremen.de•Internet-Adresse: http://www.laender-analysen.de/russland/ 


\section{Kostenlose E-Mail-Dienste der Forschungsstelle Osteuropa und ihrer Partner auf www.laender-analysen.de}

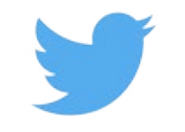

@laenderanalysen

Die Länder-Analysen bieten regelmäßig im kostenlosen Abonnement kompetente Einschätzungen aktueller politischer, wirtschaftlicher, sozialer und kultureller Entwicklungen in Ostmitteleuropa und der GUS. Sie machen das Wissen, über das die wissenschaftliche Forschung in reichem Maße verfügt, für Politik, Wirtschaft, Medien und die interessierte Öffentlichkeit verfügbar. Autoren sind internationale Fachwissenschaftler und Experten.

Die einzelnen Länder-Analysen werden von der Forschungsstelle Osteuropa an der Universität Bremen und der Deutschen Gesellschaft für Osteuropakunde jeweils mit unterschiedlichen Partnern und Sponsoren herausgegeben. Die Redaktionen der Länder-Analysen bestehen aus Wissenschaftlern mit langjähriger Forschungserfahrung.

Die Länder-Analysen bieten regelmäßig Kurzanalysen zu aktuellen Themen, ergänzt um Grafiken und Tabellen sowie Dokumentationen. Zusätzlich gibt es eine Chronik aktueller Ereignisse. Alle Länder-Analysen sind auch mit Archiv und Indizes online verfügbar unter $<$ www.laender-analysen.de $>$.

\section{Belarus-Analysen}

Erscheinungsweise: zweimonatlich

Abonnement unter: <http://www.laender-analysen.de/belarus/>

\section{Caucasus Analytical Digest}

In englischer Sprache. Erscheinungsweise: monatlich

Abonnement unter: <http://www.css.ethz.ch/publications/newsletter_CAD_EN>

\section{Polen-Analysen}

Erscheinungsweise: zweimal monatlich

Abonnement unter: <http://www.deutsches-polen-institut.de/newsletter/polen-analysen/>

\section{Russland-Analysen}

Erscheinungsweise: zweiwöchentlich

Abonnement unter: <http://www.laender-analysen.de/russland/>

\section{Russian Analytical Digest}

In englischer Sprache. Erscheinungsweise: zweimal monatlich

Abonnement unter: $<$ http://www.css.ethz.ch/publications/newsletter_RAD_EN>

\section{Ukraine-Analysen}

Erscheinungsweise: zweimal monatlich

Abonnement unter: <http://www.laender-analysen.de/ukraine/>

\section{Zentralasien-Analysen}

Erscheinungsweise: monatlich

Abonnement unter: <http://www.laender-analysen.de/zentralasien/>

\section{Bibliographische Dienste}

Die Bibliographien informieren über englisch- und deutschsprachige Neuerscheinungen zu Belarus, Russland, Ukraine sowie zu den zentralasiatischen und kaukasischen Staaten. Erfasst werden jeweils die Themenbereiche Politik, Außenpolitik, Wirtschaft und Soziales.

Erscheinungsweise: viermal jährlich

Abonnement unter: <http://www.laender-analysen.de/bibliographies/belarus.php $>,<$ http://www.laender-analysen. de/bibliographies/russia.php>, <http://www.laender-analysen.de/bibliographies/ukraine.php>, <http://www.laenderanalysen.de/bibliographies/caucasus_ca.php> 